Article

\title{
Integration of L-Band Derived Soil Roughness into a Bare Soil Moisture Retrieval Approach from C-Band SAR Data
}

\author{
Mohamad Hamze ${ }^{1,2, *}$, Nicolas Baghdadi ${ }^{1}\left(\mathbb{D}\right.$, Marcel M. El Hajj ${ }^{3,4}$, Mehrez Zribi $^{5}\left(\mathbb{D}\right.$, Hassan Bazzi $^{1}(\mathbb{D}$, \\ Bruno Cheviron ${ }^{6}$ and Ghaleb Faour ${ }^{2}$ iD
}

1 CIRAD, CNRS, INRAE, TETIS, University of Montpellier, AgroParisTech, CEDEX 5, 34093 Montpellier, France; nicolas.baghdadi@teledetection.fr (N.B.); hassan.bazzi@inrae.fr (H.B.)

2 National Center for Remote Sensing, National Council for Scientific Research (CNRS), Riad al Soloh, Beirut 1107 2260, Lebanon; gfaour@cnrs.edu.lb

3 ITK, Cap Alpha, Avenue de l'Europe, 34830 Clapiers, France; marcel.elhajj@itk.fr

4 Hydrology, Agriculture and Land Observation Group (HALO), Water Desalination and Reuse Center, Division of Biological and Environmental Sciences and Engineering, King Abdullah University of Science and Technology (KAUST), Thuwal 23955-6900, Saudi Arabia

5 CESBIO, University of Toulouse, CNES/CNRS/INRAE/IRD/UPS, 31400 Toulouse, France; mehrez.zribi@ird.fr

6 UMR G-EAU, INRAE, 34090 Montpellier, France; bruno.cheviron@inrae.fr

* Correspondence: mohamad.hamze@inrae.fr; Tel.: +33-4-6704-6300

Citation: Hamze, M.; Baghdadi, N.; El Hajj, M.M.; Zribi, M.; Bazzi, H.;

Cheviron, B.; Faour, G. Integration of L-Band Derived Soil Roughness into a Bare Soil Moisture Retrieval Approach from C-Band SAR Data. Remote Sens. 2021, 13, 2102. https:// doi.org $/ 10.3390 /$ rs 13112102

Academic Editor: Luca Brocca

Received: 6 April 2021

Accepted: 25 May 2021

Published: 27 May 2021

Publisher's Note: MDPI stays neutral with regard to jurisdictional claims in published maps and institutional affiliations.

Copyright: (c) 2021 by the authors. Licensee MDPI, Basel, Switzerland. This article is an open access article distributed under the terms and conditions of the Creative Commons Attribution (CC BY) license (https:// creativecommons.org/licenses/by/ $4.0 /)$.
Abstract: Surface soil moisture (SSM) is a key variable for many environmental studies, including hydrology and agriculture. Synthetic aperture radar (SAR) data in the C-band are widely used nowadays to estimate SSM since the Sentinel-1 provides free-of-charge C-band SAR images at high spatial resolution with high revisit time, whereas the use of L-band is limited due to the low data availability. In this context, the main objective of this paper is to develop an operational approach for SSM estimation that mainly uses data in the C-band (Sentinel-1) with L-bands (ALOS/PALSAR) as additional data to improve SSM estimation accuracy. The approach is based on the use of the artificial neural networks (NNs) technique to firstly derive the soil roughness (Hrms) from the L-band (HH polarization) to then consider the L-band-derived Hrms and C-band SAR data (VV and VH polarizations) in the input vectors of NNs for SSM estimation. Thus, the Hrms estimated from the L-band at a given date is assumed to be constant for a given times series of C-band images. The NNs were trained and validated using synthetic and real databases. The results showed that the use of the L-band-derived Hrms in the input vector of NN in addition to C-band SAR data improved SSM estimation by decreasing the error (bias and RMSE), mainly for SSM values lower than 15 vol.\% and regardless of Hrms values. Based on the synthetic database, the NNs that neglect the Hrms underestimate and overestimate the SSM (bias ranges between -8.0 and 4.0 vol.\%) for Hrms values lower and higher than $1.5 \mathrm{~cm}$, respectively. For Hrms $<1.5 \mathrm{~cm}$ and most SSM values higher than $10 \mathrm{vol} . \%$, the use of Hrms as an input in the NNs decreases the underestimation of the SSM (bias ranges from -4.5 to 0 vol. \%) and provides a more accurate estimation of the SSM with a decrease in the RMSE by approximately 2 vol.\%. Moreover, for Hrms values between 1.5 and $2.0 \mathrm{~cm}$, the overestimation of SSM slightly decreases (bias decreased by around 1.0 vol.\%) without a significant improvement of the RMSE. In addition, for Hrms $>2.0 \mathrm{~cm}$ and SSM between 8 to 22 vol. $\%$, the accuracy on the SSM estimation improved and the overestimation decreased by 2.2 vol.\% (from 4.5 to 2.3 vol.\%). From the real database, the use of Hrms estimated from the L-band brought a significant improvement of the SSM estimation accuracy. For in situ SSM less than 15 vol.\%, the RMSE decreased by 1.5 and 2.2 vol.\% and the bias by 1.2 and 2.6 vol. \%, for Hrms values lower and higher than $1.5 \mathrm{~cm}$, respectively.

Keywords: soil moisture; surface roughness; SAR; L-band; C-band; ALOS/PALSAR; Sentinel-1; artificial neural networks 


\section{Introduction}

Soil surface characteristics, particularly the moisture content and the surface roughness, play a major role in a wide range of applications including hydrology, agronomy, crop planning and crop modelling. Even though the surface soil moisture (SSM) can be estimated with a high accuracy through ground measurements, the installation and maintenance of the sensors can be very time- and labor-consuming. The measurements carried out with dielectric probes are accurate only at the point of measurement; therefore, point-based measurements are not relevant to represent the spatial distribution of SSM, which varies in space and time [1]. Currently, remote sensing observations from space provide operational tools for mapping the spatial and temporal variations of SSM over vast areas [2-8], which is considered a crucial concern for land-water management strategies and policy decision makers.

Over the past four decades, several studies have shown the great potential of synthetic aperture radar (SAR) data for SSM mapping at an agricultural plot scale with high revisit time [5,9-12]. Even though SAR data in the X-, C- and L-bands have been widely used in numerous research projects [13-18], only SAR data in the C-band are used today in operational approaches for SSM retrieving. In the case of bare soils, the SAR backscattering coefficient $\left(\sigma^{0}\right)$ depends on the dielectric constant of the superficial surface layer and the soil roughness $[4,19,20]$, as well as the SAR configuration (frequency, incidence angle and polarization) $[16,20]$. In the presence of vegetation, the canopy cover contributes to $\sigma^{0}$ through soil attenuation and direct scattering [5]. Several studies have analyzed the sensitivity of the SAR signal to SSM and surface roughness (defined mainly by the root mean surface height (Hrms)), according to different instrumental SAR configurations (incidence angle, polarization and radar wavelength) [4,21-24]. Aubert et al. [25] studied the effect of the radar wavelength in the C-and X-bands on the sensitivity of the radar signal to SSM. The results have shown that the sensitivity in the $\mathrm{X}$-band $(0.35 \mathrm{~dB} / \mathrm{vol} . \%)$ is twice as high as in the C-band ( $0.16 \mathrm{~dB} / \mathrm{vol} . \%)$. In addition, the L-band observations have approximately the same range of sensitivity to soil moisture as the C-band [26]. This high sensitivity of the $\mathrm{X}$-band radar signal to soil moisture is explained by the low effect of roughness parameters on the backscattered radar signal.

The SSM estimation was conducted using many radar backscattering models. These models can be either physical $[27,28]$ or semi-empirical [29-31]. The integral equation model (IEM), developed by Fung [27], is widely used in various inversion approaches to estimate SSM over agricultural areas $[1,5,16-18,32]$. In IEM, the $\sigma^{0}$ is expressed as a function of the soil properties (dielectric constant, soil composition, root mean surface height (Hrms), correlation length and autocorrelation function), as well as the SAR instrumental parameters (wavelength, incidence angle and polarization) [27]. In fact, the depth of penetration of the radar signal in the soil depends on its dielectric constant, which affects the moisture content in the soil. Consequently, due to the relationship between SSM and its dielectric constant, the soil could be characterized by four surface parameters (Hrms, L, autocorrelation function and SSM), in order to model and simulate $\sigma^{0}$ using IEM. Unlike empirical models, IEM does not require site-specific calibration.

Several studies reported significant differences between IEM-simulated backscattered signal and those observed from SAR data [24,32-36]. Baghdadi et al. [36-39] reported that these discrepancies were related to the uncertainties in the correlation length measurements, which are difficult to measure in situ with sufficient accuracy. To overcome inaccurate IEM simulations, Baghdadi et al. [36-39] proposed a semi-empirical calibration of IEM in the X- (in the VV), C- (HH, VV and VH) and L-bands (in the HH and VV), based on experimental data of SAR images (e.g., ALOS, ASAR, ERS, RADARSAT, TerraSAR-X and CosmoSkyMed), ground measurements, including SSM, and soil surface roughness. The calibration consisted of replacing the in situ measured correlation length $(\mathrm{L})$ by a fitting parameter (Lopt) in order to minimize the difference between the simulations and SAR data. It was found that the Lopt is dependent on the soil surface roughness and the sensor's parameters [37]. The robustness of the empirical calibration was reported in different 
studies $[25,32,40-42]$ showing a good match between the simulated and the SAR data. Eventually, the modified IEM led to an SSM estimation accuracy of 3 vol.\% with SAR data in the X-band $[14,15,32]$, approximately 4 to 6 vol. $\%$ in the C-band $[18,40,42,43]$ and $5.3 \mathrm{vol} . \%$ in the L-band [1]. Additionally, the calibration allowed the reduction of the input parameters for the IEM. The soil can, therefore, be characterized by just two surface parameters (Hrms and SSM) instead of four (Hrms, correlation length, autocorrelation function and SSM), which increases the model's applicability [37].

Considerable progress has been made in mapping SSM through SAR data, however, many fundamental questions remain about the accuracy of the estimations that depend on the sensitivity of the radar signal to the different soil properties, mainly soil roughness and soil moisture. For instance, Altese et al. [44] have shown that over bare soil fields, the effect of surface roughness is greater than the effect of SSM on the radar signal in the C-band. Thus, estimating the SSM from SAR data without accounting for Hrms contribution would lead to inaccurate SSM estimations. El Hajj et al. [5] used the artificial neural network (NNs) technique to invert C-band data and estimate the SSM without accounting for Hrms in the retrieval approach (Hrms was not in the input vector of the NNs). Results showed that the accuracy on SSM estimation is related to Hrms parameters. Indeed, the in situ SSM was underestimated by $-10 \mathrm{vol} . \%$ for Hrms lower than $1 \mathrm{~cm}$ and overestimated by 9 vol. $\%$ with an RMSE of 5 vol. \% for Hrms between 2 and $3.8 \mathrm{~cm}$. The underestimation is related to the weak SAR scattering over smooth soil (specular reflection), whereas the overestimation is a result of higher SAR backscattering due to increased soil roughness. On the other hand, the results showed unbiased estimation of SSM associated with lower RMSE for Hrms values between 1 and $2 \mathrm{~cm}$. In fact, several studies have reported that the SAR observations are highly sensitive to soil roughness [45-51]. Consequently, surface roughness and its spatial variability can greatly affect the estimation of SSM [34,52-54]. Indeed, Baghdadi et al. [34] reported that the contribution of Hrms to C-band SAR backscattering depends strongly on the SAR incidence angle. At a high incidence angle $\left(47^{\circ}\right)$, the Hrms contribution to SAR backscattering predominates the SSM ones, making it possible to classify various Hrms classes (smooth, medium and rough) over agricultural fields. Therefore, only SAR with long wavelengths (C- and L-bands, for example) and high incidence angles (above $45^{\circ}$ ) allows the classification of Hrms. Given that only a slight portion of Sentinel-1 images are available with incidences greater than $45^{\circ}$ (wide swath and incidence angles between $29^{\circ}$ and $46^{\circ}$ ), the Sentinel-1 data are not adequate to derive Hrms. Several studies showed the potential of L-band for Hrms estimation $[55,56]$. Accordingly, the combined use of Land C-band has the potential to improve SSM estimation accuracy. In such a combined use, the L-band will serve to provide Hrms estimates to be used along with the C-band backscattering to assess the SSM estimation.

The Sentinel-1 SAR sensor developed by the European Space Agency (ESA) made open source and free-of-charge C-band multi-temporal images available. With a high revisit time (6 days) and a pixel spacing of $10 \mathrm{~m}$, Sentinel- 1 allows soil moisture mapping at high spatial and temporal resolutions $[8,40,57,58]$. The commonly used method for SSM estimation is the change detection $(\mathrm{CD})$ approach $[8,58]$ and the inversion of physical or empirical models with the bias of NNs technique [5,18,34,42,59]. In fact, the estimation of SSM by inverting the SAR $\sigma^{0}$ using physical or empirical models with the use of NNs allows accounting for Hrms and vegetation contributions and thus provides more accurate SSM estimates [5,40,59].

Eventually, El Hajj et al. [1], trained the NNs using synthetic databases that were generated using WCM combined with IEM in the C- and L-bands, over a wide range of SSM (between 4 and 40 vol.\%), Hrms (between 0.5 and $3.8 \mathrm{~cm}$ ) and NDVI (between 0 and 0.7 for the C-band and 0 and 1 for the L-band) values. The overall results showed that the L-band provided slightly less accurate SSM estimates than the C-band, due to the higher sensitivity of the L-band to the soil roughness [60].

Unlike C-band SAR data, L-band images (at present ALOS-2) are not free-of-charge and hard to acquire with high revisit time (one to two images per month at best). With such 
low revisit time, L-band SAR are not adequate for operational SSM mapping since at least one image per week is required. However, they could be very powerful to estimate the Hrms since the L-band is sensitive to the soil roughness and the fact that the Hrms does not change frequently along the season, mainly over agriculture plots. Several new missions of SAR constellations operating in L-band are being developed, such as NISAR (NASA-ISRO SAR, planned to be launched in 2022), Tandem-L (German Aerospace Center, planned to be launched in 2022) and ALOS-4 (JAXA, planned to be launched in 2022). Eventually, both NISAR and Tandem-L aim to provide free-of-charge images on an average of 6 days and bi-weekly basis, respectively. Therefore, the availability of SAR images in the L-band in such a high revisit time, in the near future, illustrates its interest in many agricultural and hydrological applications, mainly estimation approaches for soil properties.

At the moment, an average of one to two ALOS-2 SAR L-band images, which are more suitable for Hrms estimation that can be measured at reasonable time intervals, are available per month compared to several Sentinel-1 images in the C-band over the same month, which allow, with a high revisit time, to grasp the temporal variability of SSM trends. The aim of this study is to evaluate the potential of combining C- and L-bands to improve the accuracy of SSM estimations over vast bare soil agricultural areas. The paper focuses on the SSM estimation from the C-band while considering the L-band-derived Hrms as additional input to the inversion approach in order to provide more accurate SSM. Therefore, the L-band-derived Hrms will be considered stable over a period of two consecutive L-band acquisitions where several C-band SAR images are acquired. The proposed approach uses NNs technique. Thus, two cases will be compared: (1) SSM estimation from C-band data by neglecting Hrms in the inputs vector to the NNs and (2) SSM estimation by integrating the L-band-derived Hrms in the input vector to the NNs for SSM estimation from C-band. First, synthetic database of $\sigma^{0}$ for a wide range of soil conditions will be generated in the C-and L-bands using the modified IEM [36-39]. Furthermore, the database is divided into two equal sub-databases, one for NNs training and one for NNs validation. In addition, the performance of the trained NNs was evaluated using the real SAR observations in the C- and L-bands, as well as in situ measurements of soil parameters (SSM and Hrms). After a description of the synthetic and real datasets used in Section 2, Section 3 presents the methodology developed. The analysis of the inversion results of the synthetic and the real databases are described in Section 4, followed by a discussion in Section 5. Finally, the main conclusions are presented in Section 6.

\section{Dataset Description}

\subsection{Real Data}

In the present study, a real database collected in Southern France at a study site near Montpellier have been used. The database is composed of real SAR data acquired from ALOS-2/PALSAR-2 and Sentinel-1 sensors, as well as in situ measurements of SSM (between 7.0 and $32.65 \mathrm{vol} . \%$ ) and Hrms (between 0.5 and $3.8 \mathrm{~cm}$ ) for bare agricultural fields. This database will serve to validate our SSM estimation approach.

\subsubsection{Study Site}

The study area is located in the Southeast of France, over the Occitanie region (centered on $3.80^{\circ} \mathrm{E}$ and $43.67^{\circ} \mathrm{N}$ ) (Figure 1). The site is characterized by a flat terrain composed of forests, vineyards and agricultural areas. The area is known for its Mediterranean climate, with average air temperatures ranging from $3{ }^{\circ} \mathrm{C}$ to $29^{\circ} \mathrm{C}$ and a rainy season occurrence between October and March. The recorded average cumulative rainfall is about $750 \mathrm{~mm}$. Reference plots with only bare soils, characterized by a sandy loam soil texture [61], were selected to perform the experiment. 


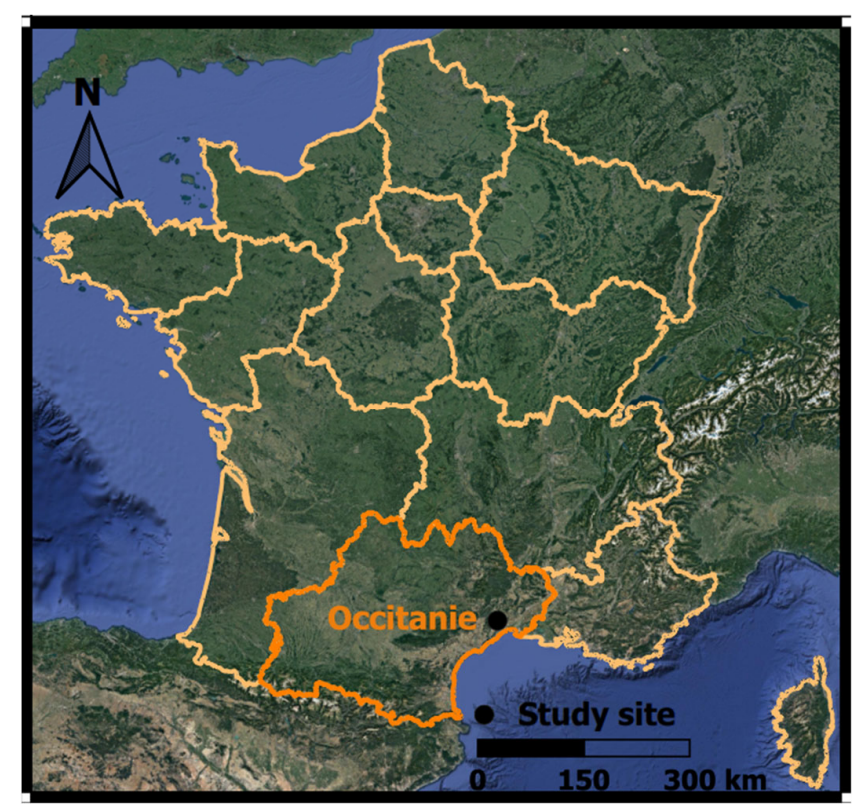

Figure 1. Location of the study site in France.

\subsubsection{Real SAR Data}

Twenty SAR images in the C-band (wavelength $=5.6 \mathrm{~cm}$ ) were acquired from the Sentinel-1 (S1) constellation in the period between February 2017 and July 2018 where each image correspond to the date of the performed in situ SSM and Hrms measurements (Table 2). The S1 images were downloaded from the Copernicus website (https: / scihub. copernicus.eu/. Accessed 1 November 2020) with a pixel spacing of $10 \mathrm{~m} \times 10 \mathrm{~m}$ generated from the Level-1 Ground Range Detected product (GRD). Additionally, the acquisition mode of the images was the Interferometric Wide (IW) swath provided in VV and VH polarizations and an incidence angle of approximately $39^{\circ}$ over the study area.

Moreover, five ALOS-2 images acquired by the Phased Array Synthetic Aperture Radar (PALSAR-2) in the L-band (wavelength $=22.9 \mathrm{~cm}$ ) between February 2017 and July 2018 (Table 1) have been used. The ALOS-2 SAR images are in dual- and quadpolarizations with pixels' size of $6 \mathrm{~m} \times 6 \mathrm{~m}$ and $3 \mathrm{~m} \times 3 \mathrm{~m}$, respectively. In this study, only the HH-polarized L-band data were used since the IEM is not calibrated for the L-band at cross-polarization and the L-HV backscattering signal can have values quite close to the equivalent noise added $( \pm 0.8 \mathrm{~dB})$ on $\sigma^{0}$ for smooth and/or very dry bare soils [39].

The calibration of the S1 and ALOS-2 images was realized using the Sentinel-1 Toolbox (S1TBX), developed by the European Spatial Agency (ESA). The calibration of the SAR-derived data is executed through a pre-processing procedure that includes thermal noise removal, radiometric and geometric calibration and speckle filtering $[17,62]$. This procedure results in converting the digital number values extracted from SAR images into backscattering coefficient $\left(\sigma^{0}\right)$ and ortho-rectifying the images. Furthermore, the mean backscattering coefficients were calculated in a linear scale for each reference plot by averaging the values of all pixels within that plot. 
Table 1. Characteristics and acquisition dates of SAR images.

\begin{tabular}{|c|c|c|c|c|}
\hline $\begin{array}{c}\text { Date } \\
\mathrm{dd} / \mathrm{mm} / \mathrm{yyyy}\end{array}$ & Sensor & Polarizations & Incidence Angle & Pixel Size $\mathbf{m} \times \mathbf{m}$ \\
\hline $18 / 02 / 2017$ & Sentinel-1 & $\mathrm{VV}+\mathrm{VH}$ & 38.4 & $10 \times 10$ \\
\hline $19 / 02 / 2017$ & ALOS-2 & $\mathrm{HH}+\mathrm{HV}$ & 37.3 & $6 \times 6$ \\
\hline $24 / 02 / 2017$ & Sentinel-1 & $\mathrm{VV}+\mathrm{VH}$ & 38.6 & $10 \times 10$ \\
\hline $02 / 03 / 2017$ & Sentinel-1 & $\mathrm{VV}+\mathrm{VH}$ & 38.6 & $10 \times 10$ \\
\hline $08 / 03 / 2017$ & Sentinel-1 & $\mathrm{VV}+\mathrm{VH}$ & 38.6 & $10 \times 10$ \\
\hline $14 / 03 / 2017$ & Sentinel-1 & $\mathrm{VV}+\mathrm{VH}$ & 38.6 & $10 \times 10$ \\
\hline $20 / 03 / 2017$ & Sentinel-1 & $\mathrm{VV}+\mathrm{VH}$ & 38.5 & $10 \times 10$ \\
\hline $27 / 03 / 2017$ & Sentinel-1 & $\mathrm{VV}+\mathrm{VH}$ & 39.0 & $10 \times 10$ \\
\hline $02 / 04 / 2017$ & ALOS-2 & $\mathrm{HH}+\mathrm{HV}+\mathrm{VH}+\mathrm{VV}$ & 37.4 & $3 \times 3$ \\
\hline $08 / 04 / 2017$ & Sentinel-1 & $\mathrm{VV}+\mathrm{VH}$ & 39.1 & $10 \times 10$ \\
\hline $20 / 04 / 2017$ & Sentinel-1 & $\mathrm{VV}+\mathrm{VH}$ & 39.1 & $10 \times 10$ \\
\hline $26 / 04 / 2017$ & Sentinel-1 & $\mathrm{VV}+\mathrm{VH}$ & 39.3 & $10 \times 10$ \\
\hline $02 / 05 / 2017$ & Sentinel-1 & $\mathrm{VV}+\mathrm{VH}$ & 39.3 & $10 \times 10$ \\
\hline $09 / 05 / 2017$ & ALOS-2 & $\mathrm{HH}+\mathrm{HV}+\mathrm{VH}+\mathrm{VV}$ & 27.4 & $3 \times 3$ \\
\hline $14 / 05 / 2017$ & Sentinel-1 & $\mathrm{VV}+\mathrm{VH}$ & 39.1 & $10 \times 10$ \\
\hline $19 / 05 / 2017$ & Sentinel-1 & $\mathrm{VV}+\mathrm{VH}$ & 38.4 & $10 \times 10$ \\
\hline $01 / 06 / 2017$ & Sentinel-1 & $\mathrm{VV}+\mathrm{VH}$ & 39.1 & $10 \times 10$ \\
\hline $02 / 06 / 2018$ & Sentinel-1 & $\mathrm{VV}+\mathrm{VH}$ & 39.3 & $10 \times 10$ \\
\hline $08 / 06 / 2018$ & Sentinel-1 & $\mathrm{VV}+\mathrm{VH}$ & 39.3 & $10 \times 10$ \\
\hline $14 / 06 / 2018$ & Sentinel-1 & $\mathrm{VV}+\mathrm{VH}$ & 39.3 & $10 \times 10$ \\
\hline $22 / 06 / 2018$ & ALOS-2 & $\mathrm{HH}+\mathrm{HV}$ & 30.9 & $6 \times 6$ \\
\hline $26 / 06 / 2018$ & Sentinel-1 & $\mathrm{VV}+\mathrm{VH}$ & 39.0 & $10 \times 10$ \\
\hline $01 / 07 / 2018$ & ALOS-2 & $\mathrm{HH}+\mathrm{HV}$ & 40.5 & $6 \times 6$ \\
\hline $02 / 07 / 2018$ & Sentinel-1 & $\mathrm{VV}+\mathrm{VH}$ & 39.1 & $10 \times 10$ \\
\hline
\end{tabular}

\subsubsection{In Situ Measurements}

The in situ measurements of SSM and root mean surface height (Hrms) were performed on a total of 23 reference bare soil plots. Volumetric SSM measurements were conducted in respect to the SAR acquisition dates within a 2-hour window using a wellcalibrated TDR (Time Domain Reflectometry) probe. Twenty-five to thirty SSM measurements were performed in the top $5 \mathrm{~cm}$ of soil and averaged to obtain a mean value of SSM for each reference plot. The SSM values ranged from 7.0 to 32.65 vol. $\%$.

The soil roughness was measured only once a change in the latter was detected in the field. The measurements of the soil roughness were performed using a needle profilometer with a length of $1 \mathrm{~m}$ and a needle spacing of $1 \mathrm{~cm}$. For each plot, five parallel roughness profiles to the SAR line of sight were recorded and another five perpendicular to the line. Thus, by processing the roughness profile, the Hrms, which represents the vertical scale of the roughness, was derived. In our study, the recorded Hrms values of the reference plots varied between 0.5 and $3.8 \mathrm{~cm}$.

Our real database is composed of 78 elements of $\sigma^{0}$ in the C-band (VV and VH polarizations) and 31 elements of $\sigma^{0}$ in the L-band ( $\mathrm{HH}$ polarization), all associated with in situ measurements of SSM and Hrms. Each element of the database corresponds to a reference plot with associated measurements (SSM and Hrms) at a given SAR acquisition date.

\subsection{Synthetic SAR Data}

IEM is the most commonly used model in inversion approaches for SSM mapping. Baghdadi et al. [36-39] undertook several empirical calibrations of the IEM, based on a large experimental database composed of SAR images and ground measurements (SSM and Hrms). The calibration consisted of replacing the measured correlation length (L) by an optimized one (Lopt) estimated for each SAR configuration (polarization and frequency), Hrms and incidence angle through an empirical equation. This calibration allowed a good fit between IEM simulated backscattering and the SAR observed data (bias and RMSE of $-0.6 \mathrm{~dB}$ and $1 \mathrm{~dB}$ in the $\mathrm{C}-\mathrm{VV}, 0.3 \mathrm{~dB}$ and $2.3 \mathrm{~dB}$ in the $\mathrm{C}-\mathrm{VH}, 0.7 \mathrm{~dB}$ and $2.2 \mathrm{~dB}$ in the $\mathrm{L}-\mathrm{HH}$, respectively). At the same time, it permitted the reduction of the input parameters for the IEM model to two soil surface parameters (Hrms and SSM). Most importantly, this 
calibration reduces IEM's input soil parameters to only two (Hrms and SSM instead of Hrms, L and SSM) so that the IEM could be used for operational SSM mapping.

The modified IEM was used to generate a synthetic database of $\sigma^{0}$ in the C-band (VV and VH polarizations) and L-band ( $\mathrm{HH}$ polarization) for a range of input parameters, corresponding to the incidence angle $(\theta)$, SSM and Hrms. In Table 2, the ranges of input parameters used for the IEM simulations are given, as well as the total number of elements.

Table 2. Minimum and maximum values of the IEM input parameters.

\begin{tabular}{ccccc}
\hline Parameter & Min Value & Max Value & Step & Element Numbers \\
\hline SSM $($ Vol. $\%)$ & 6 & 36 & 2 & 16 \\
Hrms $(\mathrm{cm})$ & 0.5 & 3.8 & 0.2 & 18 \\
$\theta\left(^{\circ}\right)$ & 20 & 45 & 1 & 26 \\
Total number of elements & & & & 7488 \\
\hline
\end{tabular}

An error corresponding to the SAR observation accuracy was added to the simulated $\sigma^{0}$ in the synthetic databases in order to convey more realistic values of the simulations (better approximates to real SAR data). For Sentinel-1, this error is relative to the absolute radiometric accuracy, which is equal to $0.70 \mathrm{~dB}$ and $1.0 \mathrm{~dB}$ for $\mathrm{VV}$ and $\mathrm{VH}$ polarizations, respectively [63]. Moreover, for ALOS-2, Motohka et al. [64] reported that the absolute radiometric accuracy is less than $0.8 \mathrm{~dB}$. Correspondingly, an absolute zero-mean Gaussian noise with a standard deviation of $\pm 0.7, \pm 0.8$ and \pm 1.0 was added to the simulated $\sigma^{0}$ in the C-VV, L-HH and C-VH, respectively.

Accordingly, for each element of our database (SSM, Hrms, $\theta$ and IEM's simulated backscattering), 100 noise samples were randomly selected from the zero-mean Gaussian noise distribution. For C-VV, C-VH and L-HH, the random noise was selected from the zero-mean Gaussian with a standard deviation of $\pm 0.7, \pm 0.8$ and $\pm 1.0 \mathrm{~dB}$, respectively. The randomly selected noise values were then added to the IEM's simulated $\sigma^{0}$, and, therefore, 100 elements were generated for each element in our synthetic databases. Finally, our noisy synthetic databases, in the C-VV, C-VH and L-HH, are composed of 748,800 elements each.

Moreover, to prepare for the NNs training and validation, the noisy synthetic database was randomly divided into two equal databases: one for the neural network training (the noisy training database) and another for the neural network validation (the noisy validation database).

\section{Methodology}

In this study, the simulated $\sigma^{0}$ in the $\mathrm{C}-\mathrm{VV}, \mathrm{C}-\mathrm{VH}$ and $\mathrm{L}-\mathrm{HH}$ were used in an inversion approach for SSM and/or Hrms estimation, using the neural networks (NNs) technique. Thus, the development of the inversion approach consists of five steps:

- Generate the synthetic database of SAR backscattering coefficients $\left(\sigma^{0}\right)$ : C-VV, C-VH and L-HH.

- Add noise to simulated SAR $\sigma^{0}$ in order to make the simulated data approximately closer to real SAR data and to account for the error in the SAR observations.

- Divide the noisy synthetic database into two equal sub-databases: one for neural network training (noisy training database) and the other for neural network validation (noisy validation database).

- $\quad$ Train and test the NNs using the noisy training and validation databases, respectively.

- $\quad$ Finally, apply the trained NNs to the real SAR database to estimate SSM and Hrms.

The innovative part of our approach consists of using the L-band-derived Hrms as an additional predictive variable with the C-band SAR data for SSM estimation with NNs (Figure 2). The objective behind using L-band-derived Hrms is to investigate whether or not this would improve the estimation of SSM from C-band SAR data. Indeed, El Hajj et al [5] and Baghdadi et al. [42] showed that the C-band, without information about the Hrms, underestimates and overestimates the in situ SSM for smooth and rough surfaces, 
respectively. Due to the low availability of images in the L-band (currently low revisit time and the difficulty to obtain images for free), the acquiring C- and L-band data at the same date is very difficult. Therefore, in the developed NNs approach, we supposed that the L-band-derived Hrms is stable between two consecutive L-band acquisitions where several Sentinel-1 C-band images are acquired (Figure 2). As the Hrms will be estimated with a certain uncertainty from L-band, the NNs for only SSM estimation from C-band, in addition to the Hrms as an input, need to be trained using noisy Hrms to account for the error on the L-band-derived Hrms.

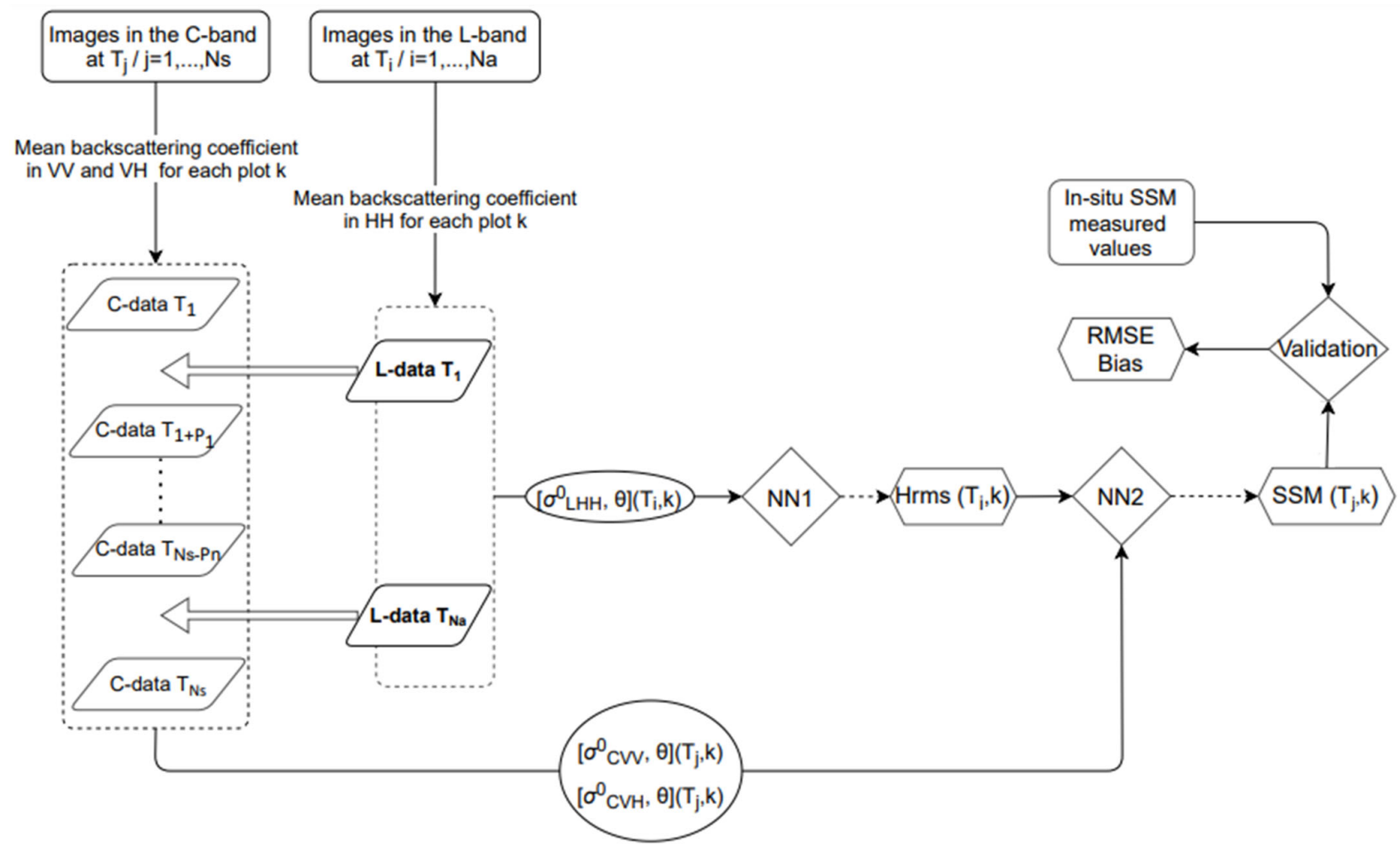

Figure 2. Methodological flowchart of the integration of soil roughness (Hrms) estimated from L-band SAR data into the NNs retrieval approach of bare soil moisture from C-band SAR data. Ti are the dates of L-band images, Tj are the dates of C-band images. Ns is the number of the Sentinel-1 images in the C-band, Na is the number of ALOS images in the L-band, P1 is the period in which estimated Hrms from L-band data is considered stable, $\theta$ is the SAR incidence angle.

Artificial neural networks were used to invert the SAR data in the C- and L-bands. Subsequently, to estimate SSM and Hrms separately or simultaneously, three NNs categories developed (Table 3):

- Category 1: Estimation of SSM from C-band SAR data with no Hrms as the input vector.

- Category 2: Estimation of Hrms from C- and L-bands SAR data separately.

- Category 3: Estimation of SSM from C-band data with Hrms in the input vector. 
Table 3. Input and output parameters for the fifteen neural networks tested in this study. Reference Hrms refers to the Hrms values used in the IEM model while the noisy Hrms refers to the reference Hrms values with an added noise.

\begin{tabular}{|c|c|c|c|c|c|}
\hline Case & Polarization & $\begin{array}{l}\text { Training } \\
\text { Database }\end{array}$ & $\begin{array}{l}\text { Validation } \\
\text { Database }\end{array}$ & Inputs & Outputs \\
\hline \multirow{5}{*}{ No a priori } & CVV+CVH: NN1 & \multirow{5}{*}{$6 \leq \mathrm{SSM} \leq 36$} & \multirow{5}{*}{$6 \leq \mathrm{SSM} \leq 36$} & \multirow{5}{*}{$\begin{array}{c}\theta, \sigma^{0} \\
\theta, \sigma^{0}, \text { Reference } \\
\text { Hrms } \\
\theta, \sigma^{0} \\
\theta, \sigma^{0} \\
\theta, \sigma^{0}, \text { Noisy Hrms }\end{array}$} & SSM \\
\hline & CVV+CVH: NN2 & & & & SSM \\
\hline & CVV+CVH: NN3 & & & & SSM, Hrms \\
\hline & LHH: NN4 & & & & Hrms \\
\hline & CVV+CVH: NN5 & & & & SSM \\
\hline \multirow{5}{*}{$\begin{array}{l}\text { A priori dry to } \\
\text { slightly wet }\end{array}$} & CVV+CVH: NN6 & & & \multirow{5}{*}{$\begin{array}{c}\theta, \sigma^{0} \\
\theta, \text { Sigma, Reference } \\
\text { Hrms } \\
\theta, \sigma^{0} \\
\theta, \sigma^{0} \\
\theta, \sigma^{0}, \text { Noisy Hrms }\end{array}$} & SSM \\
\hline & CVV+CVH: NN7 & & & & SSM \\
\hline & CVV+CVH: NN8 & $6 \leq \mathrm{SSM} \leq 30$ & $6 \leq \mathrm{SSM} \leq 25$ & & SSM, Hrms \\
\hline & LHH: NN9 & & & & Hrms \\
\hline & CVV+CVH: NN10 & & & & SSM \\
\hline \multirow{5}{*}{ A priori very wet } & CVV+CVH: NN11 & & & \multirow{5}{*}{$\begin{array}{c}\theta, \sigma^{0} \\
\theta, \sigma^{0}, \text { Reference } \\
\text { Hrms } \\
\theta, \sigma^{0} \\
\theta, \sigma^{0} \\
\theta, \sigma^{0}, \text { Noisy Hrms }\end{array}$} & SSM \\
\hline & CVV+CVH: NN12 & & & & SSM \\
\hline & CVV+CVH: NN13 & $20 \leq \mathrm{SSM} \leq 36$ & $25 \leq \mathrm{SSM} \leq 36$ & & SSM, Hrms \\
\hline & LHH: NN14 & & & & Hrms \\
\hline & CVV+CVH: NN15 & & & & SSM \\
\hline
\end{tabular}

In contrast with the category 1 , the NNs in category 3 consider the Hrms in the input vector, in order to improve the SSM estimation from C-band SAR data. Thus, a first configuration of category 3 consists of using the reference values of Hrms (without noise) in addition to $\mathrm{C}$-band SAR data $(\theta, \mathrm{C}-\mathrm{VV}$ and $\mathrm{C}-\mathrm{VH})$ as the input vector to the NN. Further, to account for the uncertainties on Hrms estimated from the L-band, the noise quantified on L-band-derived Hrms (category 2) will be added to the reference Hrms values in the input vector of category $3 \mathrm{NNs}$.

The NNs were trained using the Levenberg-Marquardt algorithm [65]. The NNs structure is characterized by two hidden layers with 20 neurons each [17]. The first and second hidden layers were associated with linear and tangent sigmoid activation functions, respectively. El Hajj et al. [5] conducted several trials by using all possible combinations of transfer function types (linear, tangent sigmoid and log sigmoid). They started up with a $\mathrm{NN}$ with one hidden layer of 10 neurons, then increased gradually the number of neurons and hidden layers and compute errors on SSM estimation. Finally, two hidden layers (linear and tangent sigmoid) with 20 neurons each have shown to provide a good estimate of SSM while keeping a reasonable computing time.

A priori information related to the soil moisture status was introduced while proceeding with the training of the NNs. In recent studies, Baghdadi et al. [17] and El Hajj et al. [5] reported that a priori knowledge of SSM has significant potential to improve the estimation and mapping of SSM. In fact, the integration of a priori information restrained the range of possible SSM estimated values, leading to more accurate SSM estimations. Indeed, the weather data (precipitation and temperature) can easily determine if the soil is either dry to slightly wet (lack of precipitation for many days before SAR acquisition) or very wet (heavy rainfall before SAR acquisition). Consequently, the NNs were trained with and without a priori information on the soil moisture conditions. Without a priori information on SSM, the NNs were developed using the entire training database (SSM between 6 and 36 vol.\%). On the contrary, with a priori information on SSM, two scenarios were developed, a priori dry to slightly wet and a priori very wet. In the case of a priori dry to slightly wet soil, the NNs were built up using the noisy training database elements with SSM between 6 and 30 vol. \%. Contrarily, in the case of a priori very wet soil conditions, the NNs were developed using the noisy training database elements with SSM between 20 and 36 vol.\%. 
An overlap of 10 vol.\% on SSM is considered between the dry to slightly wet and very wet training databases of the NNs. To sum up, 15 neural networks were developed (Table 3).

The error on L-band-derived Hrms from NN4, NN9 and NN14 will be used to define the standard deviation of the zero-mean Gaussian noise (Section 4.1.3) that will be added to the noisy Hrms in the input vector of NN5, NN10 and NN15 (NNs to estimate SSM).

Finally, these trained NNs will be applied to real SAR data. First, ALOS data will be used for estimating Hrms. Next, Sentinel-1 data will be used in addition to the Lband-derived Hrms in order to assess the potential of accuracy improvement of the SSM estimation in comparison to NNs, which do not consider the Hrms in the SSM estimation process.

After the training process, the noisy validation database is used for the estimation of SSM and/or Hrms. The difference between estimated parameters and reference parameters was computed and the error studied by means of the bias (estimated value - reference value) and the Root Mean Square Error (RMSE).

\section{Results}

\subsection{Inversion Results on the Synthetic Database}

The trained neural networks (Table 3) were applied on the noisy validation database and the accuracy of the estimated SSM were evaluated and compared to the reference SSM.

The results obtained from the NNs that estimate SSM (only) from the C-band data without the use of Hrms in the input vector (NN1, NN6 and NN11) and with the use of reference Hrms (known without an error) in the input vector (NN2, NN7 and NN12) are presented in Section 4.1.1. Moreover, the NNs developed to estimate the Hrms from the C-band (NN3, NN8 and NN13) are presented in Section 4.1.2. Then, the results of the NN4, NN9 and NN14, trained for the estimation of the Hrms from the L-band, are illustrated in Section 4.1.3. Finally, in Section 4.1.4, the potential of improving SSM estimation from the C-band using noisy Hrms in the input vector is investigated based on the comparison of the results of the NNs with no Hrms in the input vector and NNs with a noisy Hrms in the input vector (NN5, NN10 and NN15).

\subsubsection{SSM Estimation Using C-Band Data rms}

The performance of the NNs for SSM estimation from the C-band with and without reference Hrms in the input vector is shown in Figure 3. For NN1 and NN2 (no a priori information on SSM), the accuracy computation was performed using the whole validation database (SSM between 6 and 36 vol.\%). The NN1, built neglecting the Hrms contribution to SAR backscattering and thus the consequences on SSM estimation, overestimates the reference SSM values by 0.6 vol. \% with an RMSE of 4.33 vol.\% (Figure 3a). Additionally, the NN2 that considers the reference Hrms as an input overestimates the SSM values by 0.22 vol. \% with an RMSE of 2.41 vol.\% (Figure $3 b$ ).

In addition, with the use of a priori information on SSM in dry to slightly wet soil conditions, the NN6 slightly overestimates the SSM by 0.84 vol.\% with an RMSE of 3.20 vol. \% for SSM values lower than 25 vol.\% (Figure 3c). Moreover, with the consideration of the reference Hrms in the NN input vector, the accuracy of the estimates is improved. Indeed, the use of NN7 improves the accuracy of the SSM estimations, decreasing the bias by $0.48 \mathrm{vol} . \%$ and the RMSE by $1.37 \mathrm{vol} . \%$ (Figure $3 \mathrm{~d}$ ) in comparison to the results obtained with NN6. Such improvement with the use of Hrms in the input vector is not observed in the case of a priori very wet information on SSM (Figure 3e,f) because the SAR signal is not sensitive to SSM values higher than 30-35 vol.\%. Indeed, the NN11 (a priori very wet information and discarding Hrms from the input vector) slightly underestimates the reference SSM values (between 25 and 36 vol.\%) by -0.59 vol. \% with an RMSE of 3.80 vol.\% (Figure 3e), while the NN12 (a priori very wet information with Hrms in the input vector) yields slightly smaller bias (-0.12 vol.\%) and RMSE (3.01 vol.\%) (Figure 3f). 


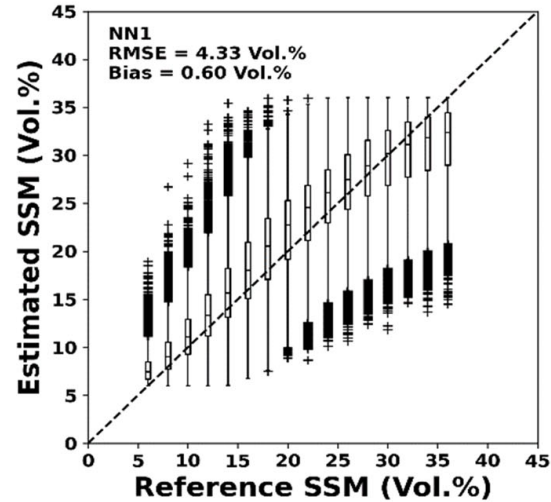

(a)

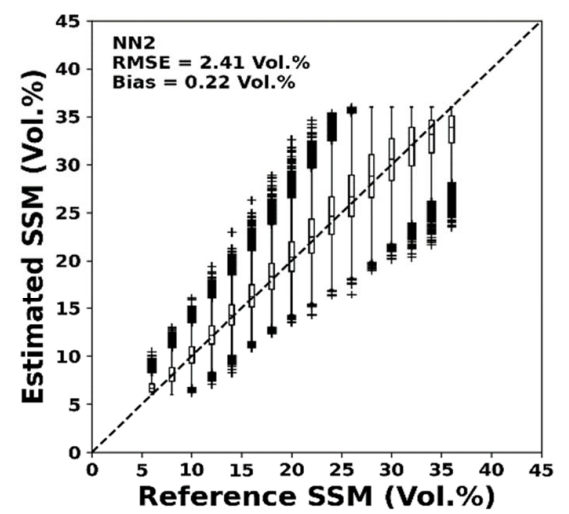

(b)

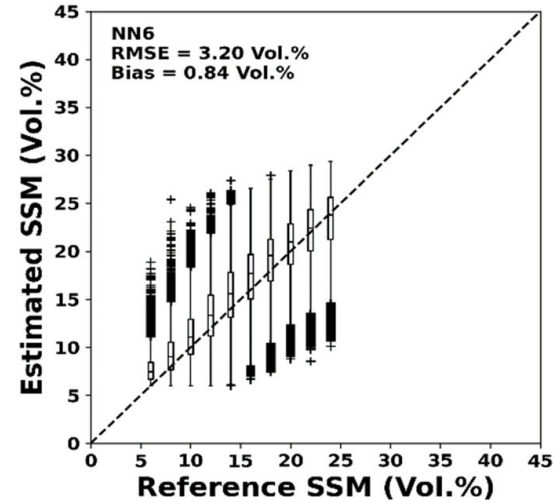

(c)

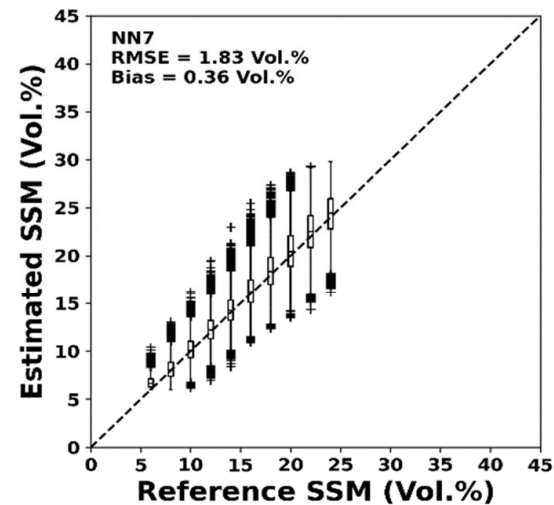

(d)

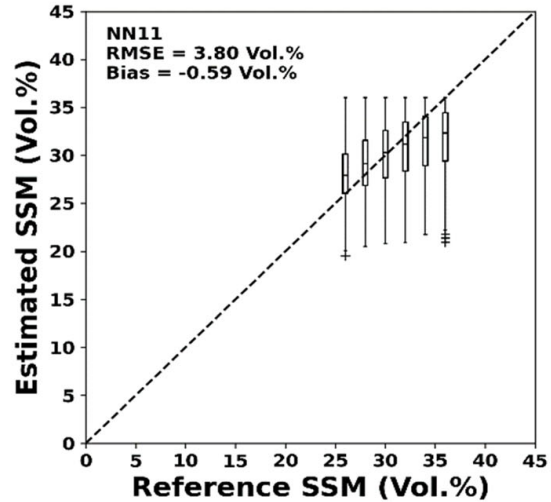

(e)

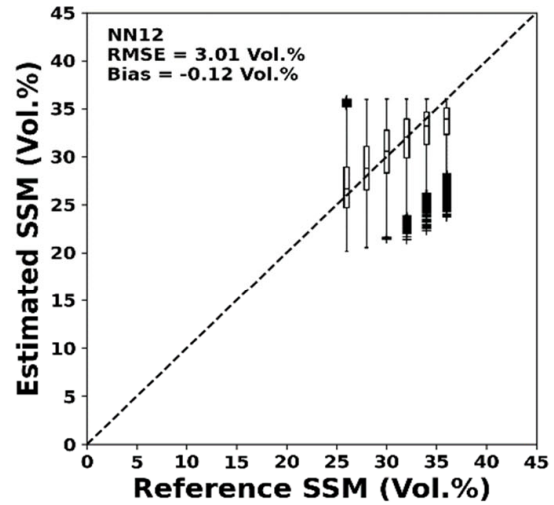

(f)

Figure 3. Estimated SSM as a function of the reference SSM using synthetic C-band data. (a) NN without using Hrms in input vector and no a priori information on SSM; (b) NN with reference Hrms (known without error) in input vector and no a priori information on SSM; (c) NN without using Hrms in input vector but using a priori information on SSM dry to slightly wet soil conditions; (d) NN with reference Hrms in input vector and a priori information on SSM dry to slightly wet soil conditions; (e) NN without using Hrms in input vector but using a priori information on SSM in very wet soil conditions; (f) NN with reference Hrms in input vector and a priori information on SSM in very wet soil conditions. The non-filled boxes represent the distribution of the estimation results at each class with the median line of the scores and the plus signs represent the outliers of the estimations located outside the whiskers of the box plot.

Furthermore, the evolution of the errors (i.e., bias and RMSE) was analyzed according to the reference Hrms values (Figure 4). For the NNs of the category 1 (NN1, NN6 and NN11) the results vary greatly as a function of the Hrms. As the reference Hrms increases from 0.5 to $3.8 \mathrm{~cm}$ :

- In the case of no a priori information on SSM (NN1), the bias varies from -4.1 vol.\% to 4.0 vol. $\%$ (Figure $4 \mathrm{a}$ ).

- In the case of a priori information on SSM in dry to slightly wet soil conditions (NN6, $\mathrm{SSM}<25$ vol. $\%$ ), the bias varies from -2.5 vol. $\%$ to 3.2 vol. $\%$ (Figure $4 \mathrm{a}$ ).

- In the case of a priori information on SSM in very wet soil conditions (NN11, SSM > 25 vol. $\%$ ), the bias varies from -3.6 vol. $\%$ to 2.4 vol. \% (Figure $4 \mathrm{a}$ ). 


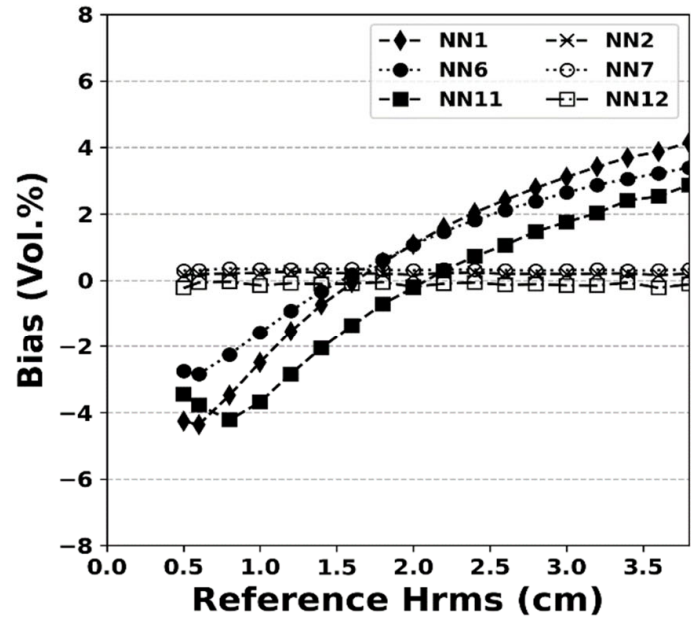

(a)

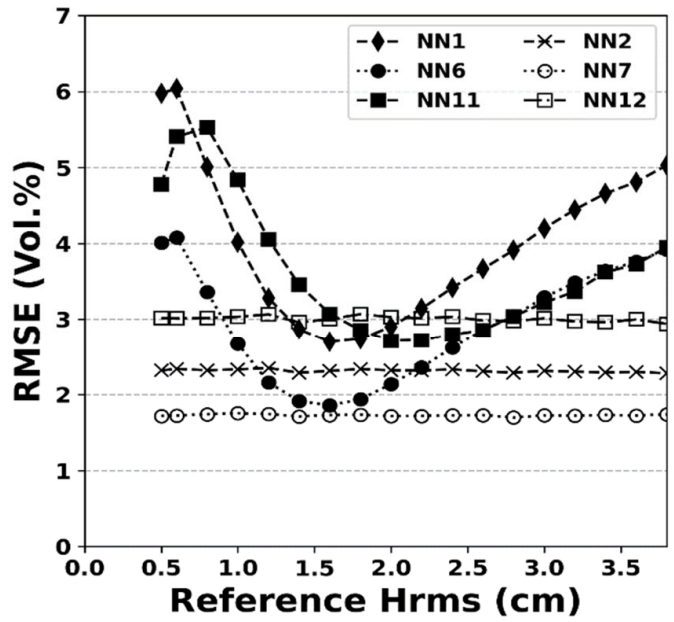

(b)

Figure 4. Evolution of bias and RMSE on the SSM estimations from synthetic C-band data as a function of reference Hrms. The NNs built are without the use of Hrms in the input (NN1 without a priori information on SSM, NN6 with a priori information on SSM in dry to slightly wet soil conditions, NN11 with a priori information on SSM in very wet soil conditions) and with the use of reference Hrms in input (NN2 without a priori information on SSM, NN7 with a priori information on SSM in dry to slightly wet soil conditions, NN12 with a priori information on SSM in very wet soil conditions). (a) Bias (estimated SSM - reference SSM); (b) RMSE on SSM.

Thus, the use of a priori information in very wet (NN11) and dry to slightly wet soil conditions (NN6) improves the accuracy of the SSM estimations, in terms of bias, by 1.5 and $0.8 \mathrm{vol} . \%$, for Hrms values greater than $2 \mathrm{~cm}$ and $1.5 \mathrm{~cm}$, respectively (Figure $4 \mathrm{a}$ ). In fact, for Hrms values below $1.5 \mathrm{~cm}$, there is an underestimation of SSM (higher for NN1, NN6 an NN11), and above Hrms $=1.5 \mathrm{~cm}$, an overestimation of SSM is observed (higher for NN1 and lower for NN11). The underestimation of SSM increases as the Hrms decreases while the overestimation of SSM increases as the Hrms increases.

As for the NNs developed with the reference Hrms in the inputs (NN2, NN7 and NN12), the results showed that the estimations of the SSM are constant and non-biased for all Hrms values (between 0.5 and $3.8 \mathrm{~cm}$ ), whether we consider or not a priori information on SSM (Figure 4a).

The evolution of the RMSE is also analyzed according to Hrms (Figure $4 \mathrm{~b}$ ). The results of NN1, NN6 and NN11 largely vary in function of the Hrms values. In fact, for Hrms values between 0.5 and $1.5 \mathrm{~cm}$, the RMSE on SSM estimates decreases from 6 to 2.8 vol.\% when no a priori information is considered on SSM (NN1), from 4 to 2 vol.\% for a priori dry to slightly wet information (NN6), and from 5.5 to 3 vol.\%, approximately, for a priori very wet information (NN11) (Figure 4b). For Hrms higher than $1.5 \mathrm{~cm}$, the RMSE greatly increases for NN1 and NN6 and slightly increases for NN11. At Hrms values of $3.8 \mathrm{~cm}$, the RMSE on the SSM estimations reaches 5 vol.\% for NN1 and 4 vol.\% for both NN6 and NN11 (Figure $4 b$ ). For the NNs of category 3 with the reference Hrms in the inputs (NN2, NN7 and NN12), the RMSE on the estimated SSM values remains constant as the Hrms increases from 0.5 to $3.8 \mathrm{~cm}$. For Hrms values between 0.5 and 3.8, the RMSE reached 3.0, 2.3 and $1.8 \mathrm{Vol} \%$ for NN12 (a priori very wet information), NN2 (no a priori information) and NN7 (a priori dry to slightly wet information), respectively (Figure 4b).

\subsubsection{Hrms Estimation Using C-Band Data}

Figure 5 shows the estimations of Hrms using NNs built with C-band data as a function of the reference Hrms values. The estimations of the Hrms are obtained with an RMSE of $0.89 \mathrm{~cm}$ when no a priori information on SSM is used (Figure 5a). Similar accuracy $(\mathrm{RMSE}=0.9 \mathrm{~cm}$ ) was observed for the NNs with a priori information on SSM in dry to slightly wet soil conditions (NN8) (Figure 5b). Finally, a slightly better RMSE on 
Hrms $(0.71 \mathrm{~cm})$ was obtained for the NNs with a priori information on SSM in very wet soil conditions (NN13) (Figure 5c).

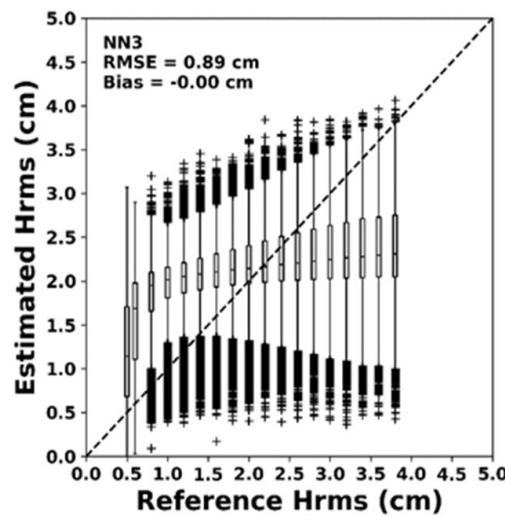

(a)

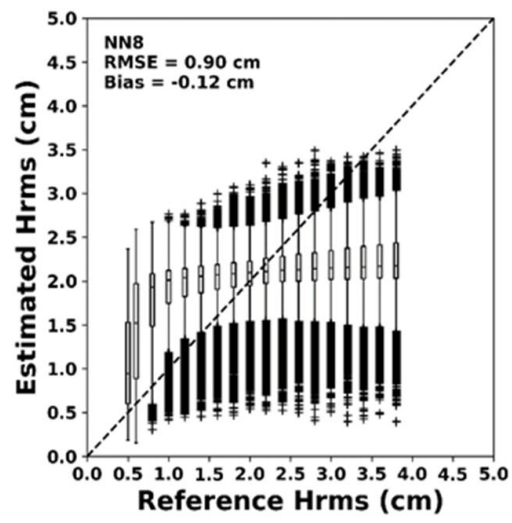

(b)

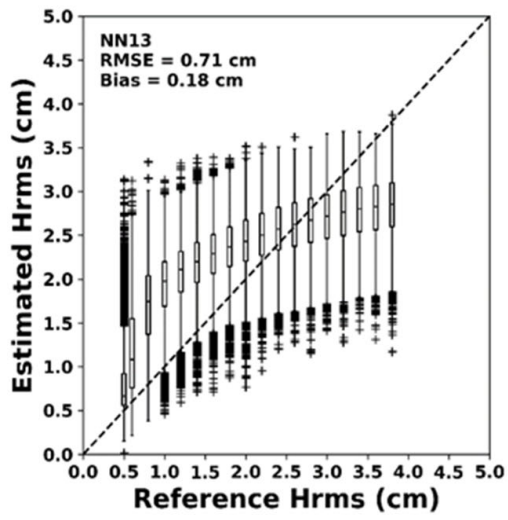

(c)

Figure 5. Estimated Hrms as a function of the reference Hrms using synthetic C-band data: (a) NN without a priori information on SSM; (b) NN with a priori information on SSM in dry to slightly wet soil conditions; (c) NN with a priori information on SSM in very wet soil conditions. The non-filled boxes represent the distribution of the estimation results at each class with the median line of the scores, and the plus signs represent the outliers of the estimations located outside the whiskers of the box plot.

\subsubsection{Hrms Estimation Using L-Band Data}

The L-band allows more accurate Hrms estimation in comparison to the C-band (Figure 6) (Section 4.1.2). In the case of no a priori information on SSM (NN4), RMSE on Hrms is $0.65 \mathrm{~cm}(0.89 \mathrm{~cm}$ for C-band) (Figure 6a). Likewise, the use of a priori information on SSM dry to slightly wet soil conditions (NN9) lead to an RMSE on Hrms of $0.6 \mathrm{~cm}$ $(0.90 \mathrm{~cm}$ for C-band) (Figure $6 \mathrm{~b})$. With a priori information on SSM in the case of very wet soil conditions (NN14), the accuracy on the Hrms estimates is improved by a factor of $2(\mathrm{RMSE}=0.35 \mathrm{~cm}$ ) compared to the results of NN4 and NN9 (Figure $6 \mathrm{c}$ ). For both NN4 and NN9, an overestimation of Hrms is observed for Hrms values lower than $2 \mathrm{~cm}$ and an underestimation of Hrms is observed for Hrms values higher than $2 \mathrm{~cm}$. Finally, the overestimation of Hrms for Hrms values $<2 \mathrm{~cm}$ and the underestimation of Hrms for Hrms values $>2 \mathrm{~cm}$ are quite low with NN14.

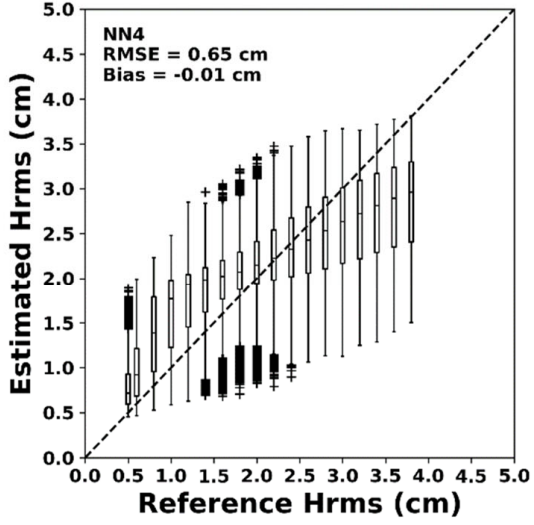

(a)

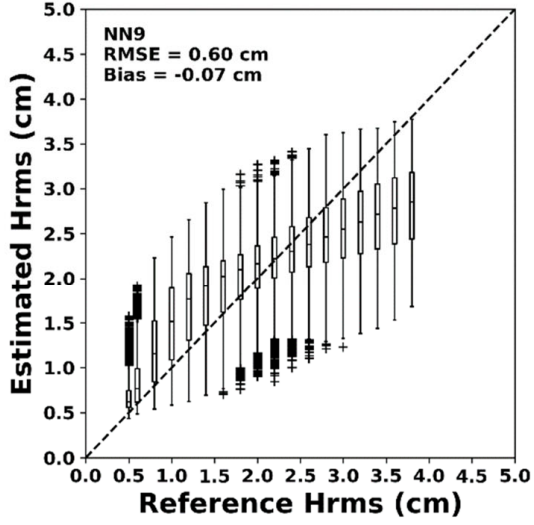

(b)

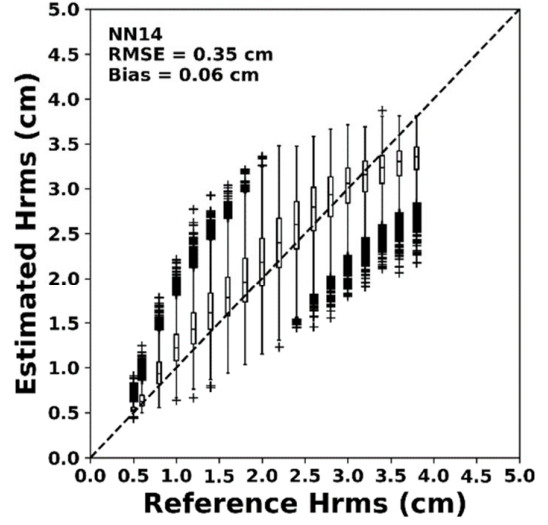

(c)

Figure 6. Estimated Hrms as a function of the reference Hrms using simulated L-band data: (a) NN without a priori information on SSM; (b) NN with a priori information on SSM in dry to slightly wet soil conditions; (c) NN with a priori information on SSM in very wet soil conditions. The non-filled boxes represent the distribution of the estimation results at each class with the median line of the scores, and the plus signs represent the outliers of the estimations located outside the whiskers of the box plot. 
Furthermore, the error on the Hrms estimations was analyzed according to the reference Hrms values (Figure 7). For both NN4 (without a priori information on SSM) and NN9 (with a priori information on SSM in dry to slightly soil wet conditions), approximately similar error behavior, according to Hrms, is reported. In fact, an overestimation is observed for Hrms values between 0.5 and $2 \mathrm{~cm}$. This overestimation increases for NN4 from 0.3 to $0.6 \mathrm{~cm}$ as Hrms increases from 0.5 to $1.0 \mathrm{~cm}$, and next decreases gradually to reach $0 \mathrm{~cm}$ for a Hrms of $2.0 \mathrm{~cm}$ (Figure 7a). For NN9, the bias on the Hrms estimates is about $0.15 \mathrm{~cm}$ lower than for NN4 for Hrms values between 0.5 and $2 \mathrm{~cm}$. Moreover, NN4 and NN9 underestimate the Hrms for reference values beyond $2.0 \mathrm{~cm}$ to reach a bias of $-1.0 \mathrm{~cm}$ for Hrms of $3.8 \mathrm{~cm}$. For a Hrms between $2 \mathrm{~cm}$ and $3.8 \mathrm{~cm}$, the overestimation of the Hrms is slightly higher with NN9 than with NN4. For NN14 (with a priori information on SSM in very wet soil conditions), an overestimation of $\mathrm{Hrms}$ of at most $0.3 \mathrm{~cm}$ is observed for Hrms between 0.5 and $3 \mathrm{~cm}$. Beyond $3.0 \mathrm{~cm}$, an underestimation is observed, and at Hrms of $3.8 \mathrm{~cm}$ the NN14 underestimates the reference Hrms by $-0.5 \mathrm{~cm}$ (Figure 7a).

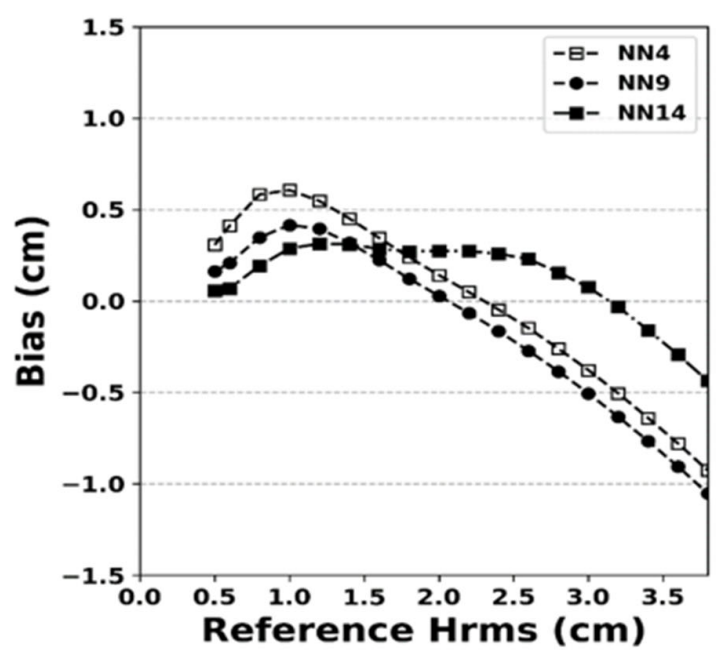

(a)

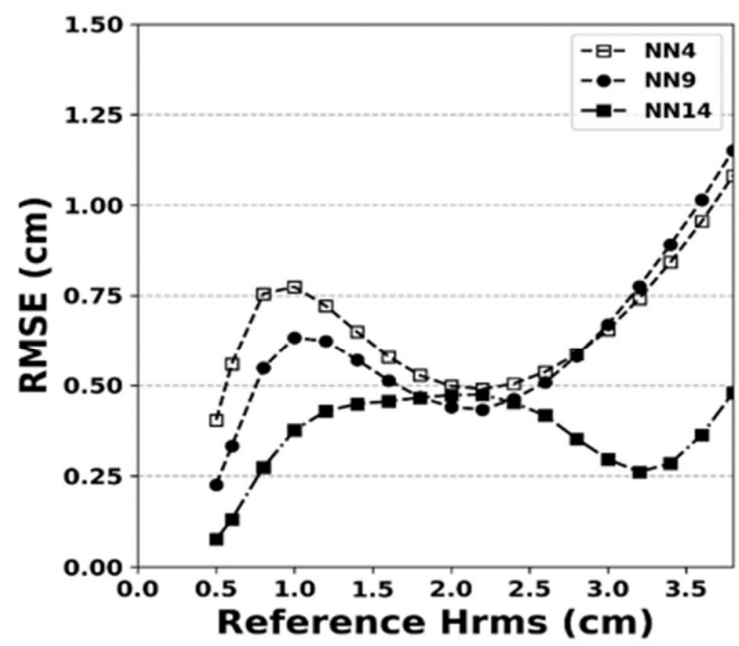

(c)

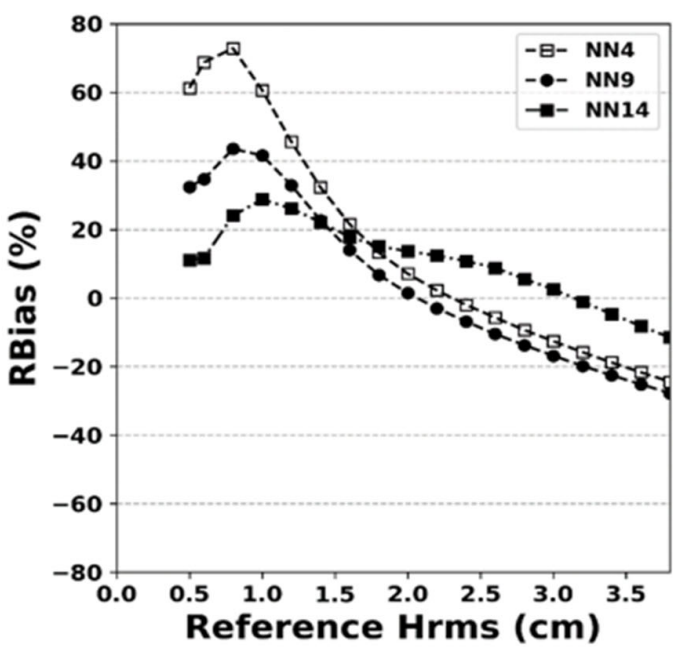

(b)

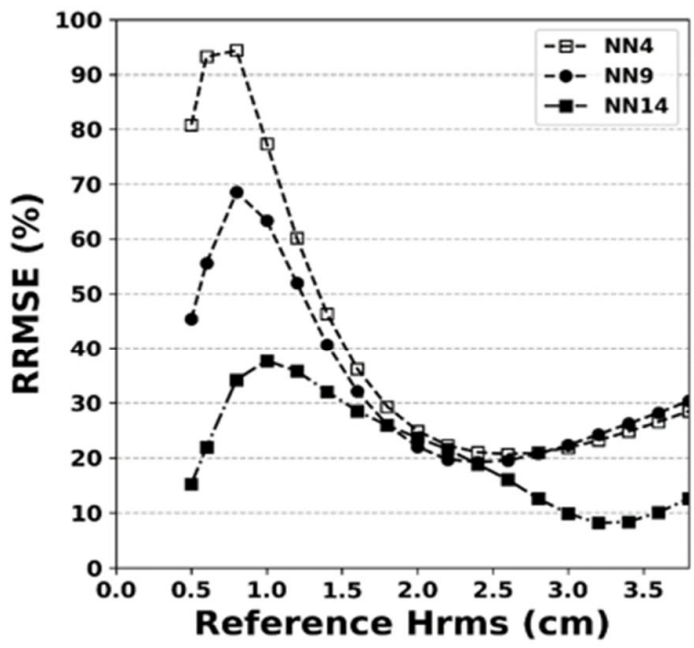

(d)

Figure 7. Error evolution on the Hrms estimations as a function of reference Hrms using simulated L-band data. The NNs used are NN4 without a priori information on SSM, NN9 with a priori information on SSM in dry to slightly wet soil conditions, NN14 with a priori information on SSM in very wet soil conditions. (a) Bias (estimated Hrms - reference Hrms); (b) RBias; (c) RMSE; (d) RRMSE on Hrms.

In addition, the relative bias (RBias \%) was computed as the bias over the average of the reference Hrms values. Figure $7 \mathrm{~b}$ shows the maximum values of RBias between 
$60 \%$ and $70 \%$ for NN4 and Hrms between 0.5 and $1 \mathrm{~cm}$. For Hrms between 1.5 and 3.8 $\mathrm{cm}$, RBias varies between $-20 \%$ and $20 \%$. In addition, for NN9 and NN14, RBias varies between $-30 \%$ and $42 \%$ and between $-10 \%$ and $28 \%$, respectively. In conclusion, the use of a priori information on SSM leads to absolute RBias which does not exceed 30\% for Hrms between 1.2 and $3.8 \mathrm{~cm}$.

Figure 7c shows that the RMSE on Hrms is much larger with NN4 and NN9 than with NN14. For NN4 and NN9, the RMSE on Hrms increases as the Hrms increases between 0.5 and $1.0 \mathrm{~cm}$. Indeed, for NN4 the RMSE increases from 0.4 to $0.75 \mathrm{~cm}$ as the Hrms increases from 0.5 to $1 \mathrm{~cm}$. Moreover, for NN9 the RMSE increases from 0.25 to $0.60 \mathrm{~cm}$ as the Hrms increases from 0.5 to $1 \mathrm{~cm}$. A decrease in RMSE on Hrms is then observed with NN4 and NN9 for Hrms values between 1.0 and $2.5 \mathrm{~cm}$ to increase again beyond 2.5 $\mathrm{cm}$ and reach its highest value of $1.15 \mathrm{~cm}$ for a Hrms of $3.8 \mathrm{~cm}$. In the case of NN14 (with a priori information on SSM in very wet soil conditions), the RMSE values are lower in comparison to NN4 and NN9 with RMSE values not exceeding $0.5 \mathrm{~cm}$ (Figure 7c).

To deeply analyze the accuracy of the Hrms estimation using the L-band data, the relative RMSE (RRMSE) was plotted (Figure 7d). The RRMSE relates the RMSE to the reference range of the variable (Hrms). Thus, it can be interpreted as a fraction (percentage) of the overall range that is typically resolved by the NNs. The RRMSE is expressed as the RMSE of the Hrms estimations over the average of reference Hrms values. The results show that the RRMSE strongly depends on the Hrms values, mainly with NN4 and NN9. For all NNs, an increasing RRMSE is observed when Hrms values range between 0.5 and $1.0 \mathrm{~cm}$. The greatest values of RRMSE using NN4, NN9 and NN14 are 94\%, 70\% and $38 \%$, respectively (Figure $7 \mathrm{~d}$ ). Then, beyond this threshold (Hrms $=1.0 \mathrm{~cm}$ ), the RRMSE tends to sharply decrease to reach $20 \%$ for Hrms $=2.5 \mathrm{~cm}$ regardless of the NN. For Hrms greater than $2.5 \mathrm{~cm}$, the RRMSE continues to decrease for NN14 to reach 10\% while it begins to slowly increase for NN4 and NN9 to reach an RRMSE of around 30\% (Figure 7d). Consequently, for most agricultural plots that typically have Hrms between 1.5 and $2.5 \mathrm{~cm}$, the RMSE on Hrms is about $0.5 \mathrm{~cm}$ with a corresponding RRMSE between $20 \%$ and $40 \%$ in the case of NNs with a priori information on SSM (NN9 and NN14).

\subsubsection{SSM Estimation Using C-Band Data and Noisy Hrms values}

In Section 4.1.1., we showed that when reference Hrms was considered in the training of the NNs (NN2, NN7, NN12), the overall accuracy on the estimations of SSM was improved compared to the NNs built neglecting the Hrms effect (NN1, NN6, NN11). Thus, in this section, we will analyze the improvement brought by the integration of Hrms estimated using the L-band data on the SSM estimations from C-band SAR data (NN4, NN9 and NN14). NNs trained with noisy Hrms in the input vector in addition to the C-band data will be tested (NN5, NN10 and NN15). Therefore, a relative noise equivalent to the uncertainty on the Hrms estimates from the L-band (Figure 7d) was added to the reference Hrms. In fact, the NN4 (no a priori information on SSM), NN9 (a priori dry to slightly wet soils) and NN14 (a priori very wet soils) exhibited an average RRMSE on the estimations of Hrms using the L-band of $41.8 \%, 34.3 \%$ and $20.7 \%$, respectively (Figure $7 \mathrm{~d}$ ). Thus, the relative accuracy on the Hrms estimates from the L-band is assumed, in this study, as $40 \%$. Consequently, the noise added on the reference Hrms values is a relative zero-mean Gaussian noise with a standard deviation of $40 \%$. Accordingly, NN5, NN10 and NN15 are trained with the noisy Hrms values along with the synthetic C-band SAR data.

Figure 8 shows that the NN5 (without a priori information on SSM) and the NN10 (a priori information in dry to slightly wet soil conditions) underestimate the SSM for Hrms values lower than $1.5 \mathrm{~cm}$. This underestimation is also observed using the NN15 (a priori information in very wet soil conditions) for Hrms $<2 \mathrm{~cm}$ (Figure $8 \mathrm{a}$ ). In fact, the bias is higher for low Hrms values ( -2.3 vol.\% with NN5 and -1.7 vol.\% NN10 for Hrms $=0.5 \mathrm{~cm}$ ). This underestimation was higher with NN1 and NN6 (neglecting the Hrms effect). In fact, for Hrms values lower than $1.5 \mathrm{~cm}, \mathrm{NN} 1$ and NN6 underestimate the reference SSM with a maximum bias of about -4 vol.\% (for Hrms $=0.5 \mathrm{~cm}$ ). At Hrms 
values greater than $1.5 \mathrm{~cm}$, the reference SSM is overestimated for the NNs without a priori information on SSM and for NNs with a priori information for dry to slightly wet soils (NN1, NN5, NN6, NN10) (Figure 8a). This overestimation increases as the Hrms values increase, with a higher error for the NNs that neglect the Hrms effect (NN1 and NN6). For SSM values greater than $25 \mathrm{vol} . \%$, the NNs with a priori information on SSM, both NN11 (Hrms neglected) and NN15 (noisy Hrms in inputs), underestimate the SSM for Hrms values ranging between 0.5 and $2 \mathrm{~cm}$. This underestimation is higher for NN11 and decreases when the Hrms increases. The bias varied between -4 and 2.7 vol. $\%$ for NN11 and between -2.3 and 2 vol. $\%$ for NN15 when the Hrms increased from 0.5 to $3.8 \mathrm{~cm}$ (Figure 8a).

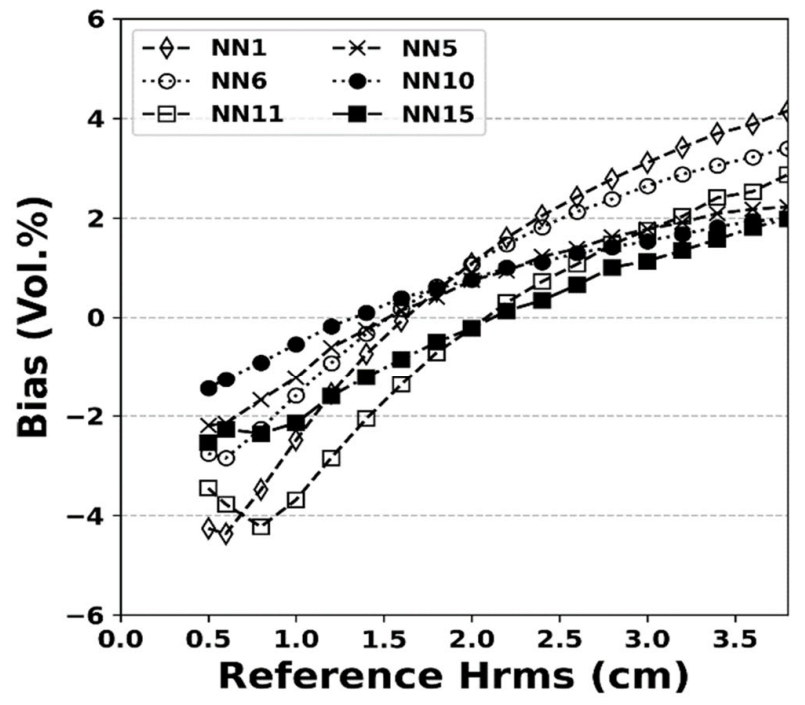

(a)

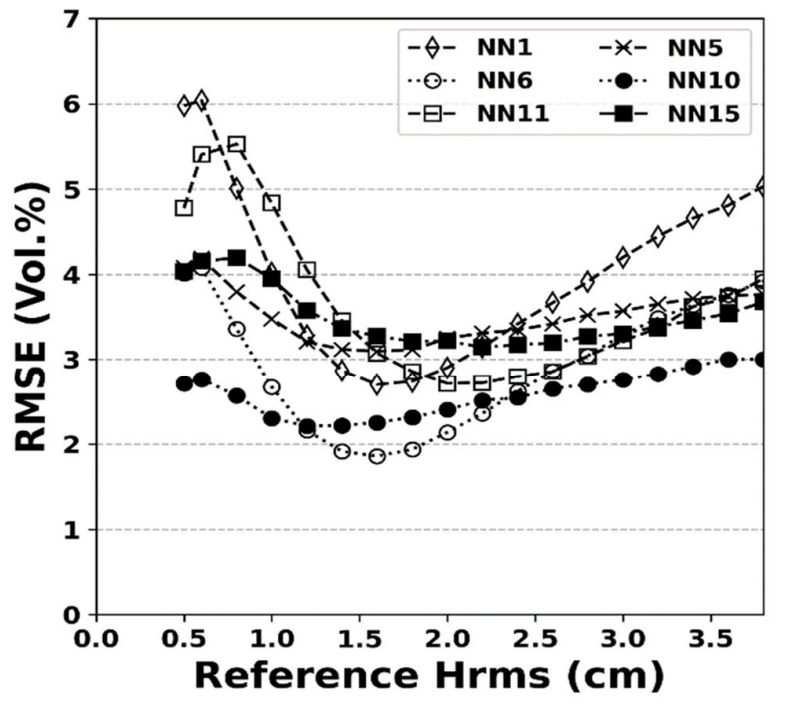

(b)

Figure 8. Error evolution on the SSM estimations as a function of reference Hrms using simulated C-band data through NNs without Hrms in the input vector (NN1 without a priori information on SSM, NN6 with a priori information on SSM in dry to slightly wet soil conditions, NN11 with a priori information on SSM in very wet soil conditions) and NNs with noisy Hrms in input (NN5 without a priori information on SSM, NN10 with a priori information on SSM in dry to slightly wet soil conditions, NN15 with a priori information on SSM in very wet soil conditions). (a) Bias (estimated SSM - reference SSM); (b) RMSE on SSM.

Figure $8 \mathrm{~b}$ illustrates the evolution of RMSE according to Hrms. In general, NN5 and NN15 resulted in approximately the same behavior of the RMSE according to Hrms (between 3 and 4 vol.\%). NN10 (with a priori information on SSM with dry to slightly wet soil conditions) shows lower RMSE values than the RMSE observed with NN5 and NN15 (RMSE between 3 and 2.2 vol.\%). On the contrary, the RMSE observed in the results of the NNs discarding the Hrms (NN1, NN6 and NN11) shows higher values for Hrms between 0.5 and $1.0 \mathrm{~cm}$ as well as between 2.5 and $3.0 \mathrm{~cm}$. More generally, the observed RMSE in the case of the NNs without considering the Hrms in inputs varies between 2 and 6 vol.\%, whereas the NNs developed with Hrms as an input generated SSM estimation with an RMSE that ranges between 2.2 and 4.2 vol.\%. Thus, considering the Hrms in the NNs training shows a significant potential in the improvement of the accuracy on the SSM estimation (lower RMSE).

\subsection{Inversion Results on the Real Database}

The neural networks (NNs) developed to estimate SSM and Hrms were evaluated using a real database composed of real SAR data in both C- and L-bands. The rainfall events records over the study area were used to determine the appropriate $\mathrm{NN}$ with the a priori information to be applied (dry to slightly wet or very wet soils conditions). The NNs with a priori information on SSM in dry to slightly wet soil conditions (NN6, NN9 and NN10) 
are applied if SAR images were acquired on a date far from a rain event or when high temperatures are recorded (quickly dried soil). The NNs with a priori information on SSM in very wet soil conditions (NN11, NN14 and NN15) are applied if SAR images are acquired after an intense rain event. Thus, for every category, the estimated values are selected based on the appropriate NN used (e.g., NN9/NN14, NN6/NN11 and NN10/NN15)

For the estimation of Hrms, NNs trained with the L-band data as inputs (NN4, NN9 and NN14) were used for the inversion of the real database. Figure 9 shows the estimated Hrms versus the in situ Hrms. The results of NN4, NN9 and NN14 showed that the use of a priori information on SSM does not improve the accuracy of the estimated Hrms from the L-band (Section 4.1.3). In fact, our real in situ database is composed of $80 \%$ of points with an SSM between 0 and 25 vol.\% (dry to slightly wet soil conditions). Therefore, relatively similar results were obtained with and without considering a priori information on SSM (Figure 9), exhibiting a slight overestimation by 0.23 to $0.26 \mathrm{~cm}$ with an RMSE ranging between 0.78 and $0.82 \mathrm{~cm}$. This overestimation observed for real data is in line with results from synthetic data where an overestimation is observed with NN4 and NN9 (Figure 6a,b), primarily for Hrms lower than $2 \mathrm{~cm}$ (this corresponds to the range of Hrms in our real database).

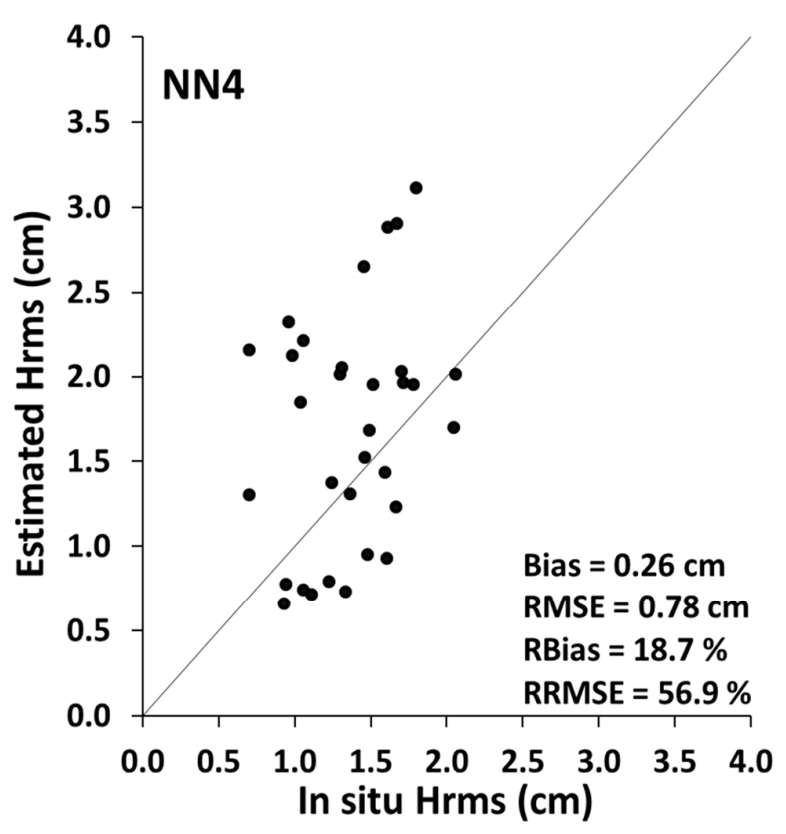

(a)

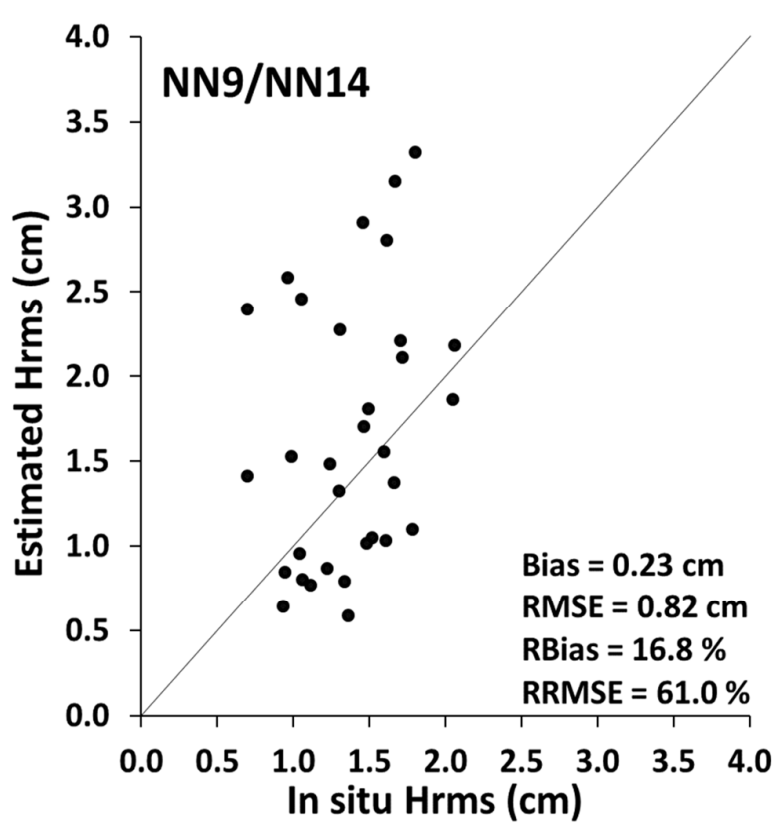

(b)

Figure 9. Retrieved Hrms using real SAR data in the L-band versus in situ measurements. (a) NN without a priori information on SSM (NN4); (b) NN with a priori information on SSM in the dry to slightly wet soil conditions (NN9) and $\mathrm{NN}$ with a priori information on SSM in very wet soil conditions (NN14).

Furthermore, the evaluation of the NNs trained for the estimation of SSM neglecting the Hrms effect (NN1, NN6, NN11) were performed using only C-band data (Figure 10ab). Moreover, the NNs built to estimate the SSM from the C-band and using L-band-derived Hrms in the input vector (NN5, NN10, NN15) were evaluated using C-band and L-band real database (Figure 10c,d). For NN1, NN6 and NN11, the results show that the use of a priori information improves the precision of the estimated SSM. Indeed, NN1 slightly underestimates the in situ SSM by -0.15 vol. $\%$ with an RMSE of $4.84 \mathrm{vol} \%$, whereas the NN6 and NN11 (with a priori information on SSM) also provide a low bias ( -0.30 vol.\%) but a higher accuracy with an RMSE of 3.94 vol.\% (Figure 10a,b). In addition, the results obtained in the inversion using NN5 (L-band-derived Hrms in the input vector) are quite similar to those obtained with NN1 with a slight underestimation by $-0.46 \mathrm{vol} \%$ and an RMSE of 4.39 vol.\% (Figure 10a,c). Eventually, the use of a priori information on SSM 
for the inversion using estimated Hrms (NN10 and NN15), improves the accuracy of the estimated SSM compared to the results obtained without a priori information on SSM (NN5) (Figure 10c,d). Therefore, the integration of the L-band-derived Hrms using a priori information on SSM provided slightly significant better estimations (bias $=-0.21$ vol. $\%$ and RMSE $=3.0 \mathrm{vol} . \%$ ) compared to the estimations obtained neglecting the Hrms in the input vector (NN6 and NN11) (Figure 10b,d). More specifically, for plots with Hrms higher than $3 \mathrm{~cm}$ (blue ellipses in Figure 10b), a high overestimation of SSM was obtained from NNs that do not consider the L-band-derived Hrms in their input vector (NN6 and NN11), whereas slightly biased SSM estimation $(-0.21 \mathrm{vol} . \%)$ was obtained from NNs that use L-band-derived Hrms in their inputs vector (NN10 and NN15). Similarly, for Hrms lower than $1 \mathrm{~cm}$ (red ellipses in Figure 10d), all the NNs underestimate the in situ SSM, with lower underestimation observed for NNs that use the L-band-derived Hrms in their input vectors (NN10 and NN15).

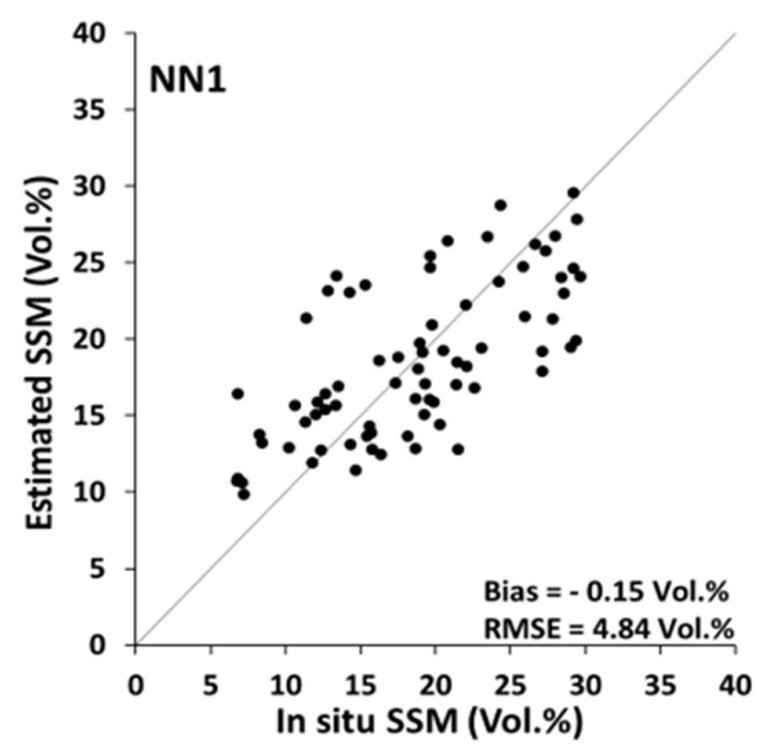

(a)

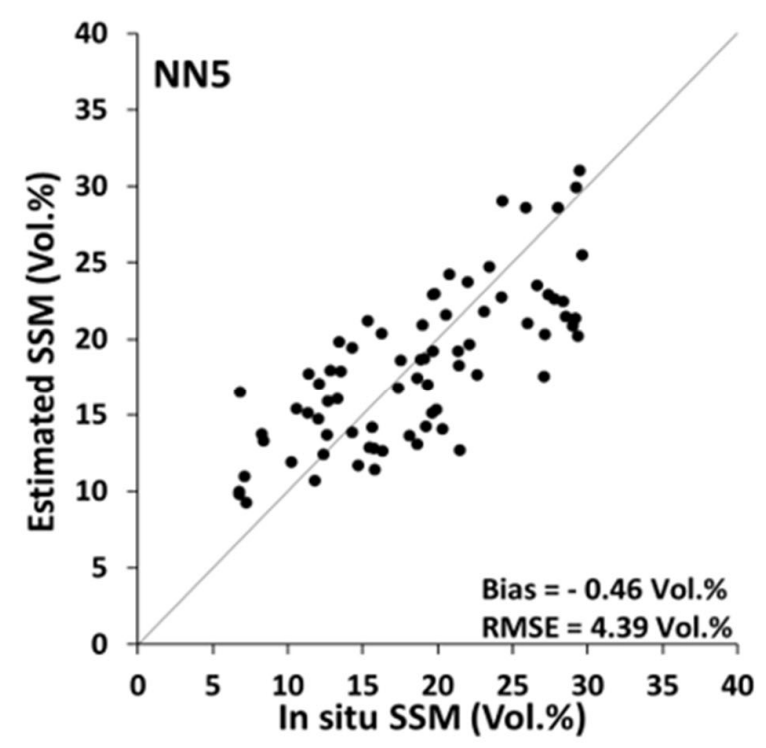

(c)

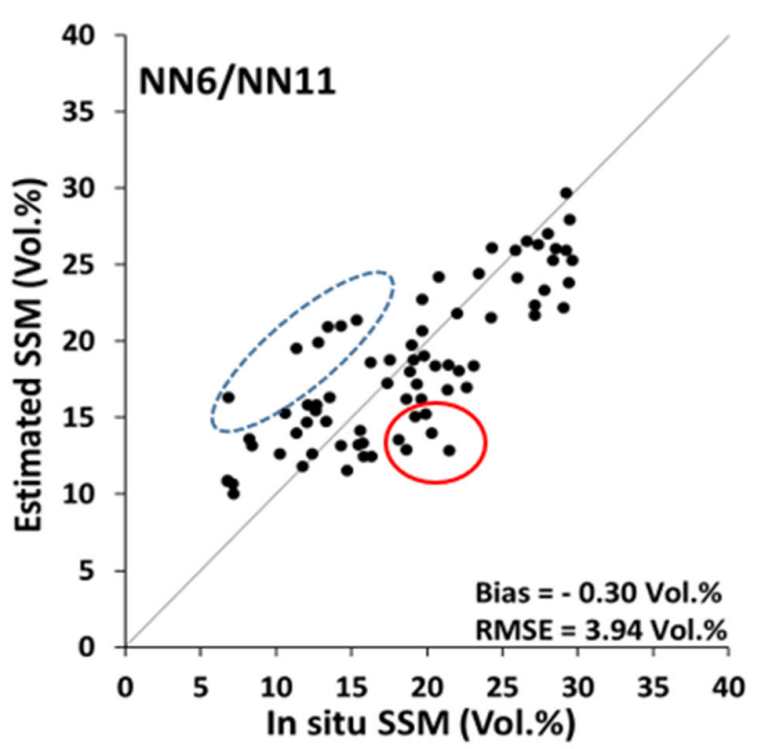

(b)

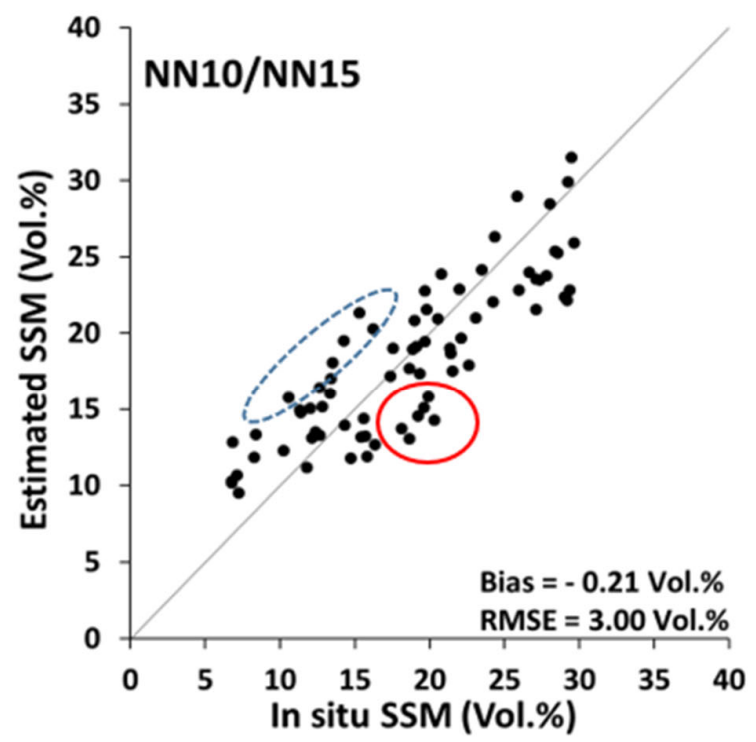

(d)

Figure 10. Retrieved SSM with the inversion performed using C-band real SAR data in the versus in situ measurements. (a) NN without Hrms in input and no a priori information on SSM; (b) NN without Hrms in input and a priori information on SSM; (c) NN with noisy Hrms in input and no a priori information on SSM; (d) NN with noisy Hrms in input and a priori information on SSM. 


\section{Discussion}

The results obtained in Sections 4.1.1 and 4.1.4 indicate that both SSM and Hrms largely influence the SSM estimation accuracy. Although acceptable retrieval results of SSM have been published in several previous studies [47,55,66-68], numerous publications reported on poor results when inverting the SAR backscattering coefficient to SSM [35,69-71]. Generally, a lack of accurate information about soil roughness was assigned as being the main source of error that caused the failure of the SSM retrieval $[60,72]$. Moreover, in a tentative experiment to improve SSM estimation, Baghdadi et al. [17] proposed an approach based on the NN technique to estimate both SSM and Hrms from polarimetric C-band SAR data. The objective was to investigate the potential of C-band SAR data to estimate the Hrms, so that the C-band-derived Hrms (with incidence angles of $34-36^{\circ}$ and $45-47^{\circ}$ ) could be used in the input vector to NNs for SSM estimation. Unfortunately, the results revealed a great difficulty in correctly estimating the soil roughness. In fact, an underestimation of in situ Hrms was obtained for Hrms values higher than $2.5 \mathrm{~cm}$, and an overestimation was observed for low and medium surface roughness $(<2.5 \mathrm{~cm})$, with an overall RMSE equal to $0.5 \mathrm{~cm}$. In addition, Satalino et al. [66] conducted a study to assess the feasibility of retrieving soil moisture content over smooth bare-soil fields using SAR data, and the results indicated that no more than two soil moisture classes can reliably be distinguished using the SAR configuration, even for the restricted roughness range considered.

Hence, to better understand the effects of SSM and Hrms on the SSM estimation accuracy, the error on SSM estimations (i.e., bias and RMSE) was plotted according to both SSM and Hrms (Figure 11). The NNs built with the use of Hrms in their input vectors (NN5, NN10, NN15) show that the knowledge of the Hrms improves the estimation accuracy of the SSM compared to the NNs that neglect the Hrms in the input vector (NN1, NN6, NN11) (Figure 11). Although, the magnitude of the improvement greatly varies with the values of Hrms and SSM. For SSM values greater than $25 \mathrm{vol} . \%$ and $\mathrm{Hrms}<1.6 \mathrm{~cm}$, the reference SSM is mainly underestimated for both NN11 and NN15 (Figure 11a,b). For Hrms values around $0.7 \mathrm{~cm}$ and SSM values $>31$ vol.\%, NN11 (no a priori information on SSM and without Hrms in the input vector) underestimates the reference SSM by up to -8 vol. $\%$ (Figure 11a). This underestimation decreases when using NN15 with a bias that reaches $-4.0 \mathrm{vol} . \%$ at the highest SSM (35 vol.\%) and an Hrms of $0.7 \mathrm{~cm}$ (Figure 11b). For Hrms $>1.6 \mathrm{~cm}$, an overestimation of SSM is observed for SSM values between 25 and $33 \mathrm{vol} . \%$, by up to 4.5 vol.\% using NN11 and a lower bias reaching 3.0 vol.\% using NN15. An underand overestimation of SSM of relatively the same order of magnitude, compared to NN1, NN6 and NN11, was also reported by El Hajj et al. [5] in a similar approach using NNs to invert data in the C-band without accounting for Hrms in the retrieval of SSM. Indeed, results showed that the accuracy of SSM estimation is related to the consideration of the Hrms in the inversion approach.

Similarly, for SSM values lower than 25 vol.\%, the SSM, with both NN6 and NN10, are underestimated when Hrms was lower or equal to $1.2 \mathrm{~cm}$ (Figure 11c,d). However, the results show that the underestimation increases when Hrms value decreases and is of lower magnitude when using Hrms as an input vector in NN10 (up to -2.5 vol.\% when Hrms $=0.5 \mathrm{~cm}$ and SSM $=25 \mathrm{vol} . \%$ ) compared to the NN6 (up to $-5.0 \mathrm{vol} . \%$ when Hrms $=0.5 \mathrm{~cm}$ and SSM $=25 \mathrm{vol} . \%$ ). When Hrms is greater than $1.2 \mathrm{~cm}$, the SSM is mainly overestimated (Figure 11c,d). This overestimation decreases when the NN10 is applied instead of NN6, with a maximum bias of 2.8 and 4.5 vol.\%, respectively. For Hrms values higher than $1.6 \mathrm{~cm}$ and a given SSM (between 6 and $24 \mathrm{vol} . \%$ ), the overestimation increases as the Hrms increases (Figure 11c,d). In fact, for Hrms values higher than $2 \mathrm{~cm}$, the increased contribution of Hrms results in a high backscattering coefficient and consequently an overestimation of SSM for dry to slightly wet soils and a slight underestimation of SSM with a low RMSE for very wet soils (SSM values between 25 and 40 vol. \%) because the SAR backscattering becomes insensitive to the SSM for SSM $>30$ vol.\%. In addition, for Hrms values less than $1 \mathrm{~cm}$ (smooth surface), the low backscattering coefficient produced by 
the smooth surface leads to a specular surface reflection of the backscattered radar signal, consequently causing an underestimation of the SSM.

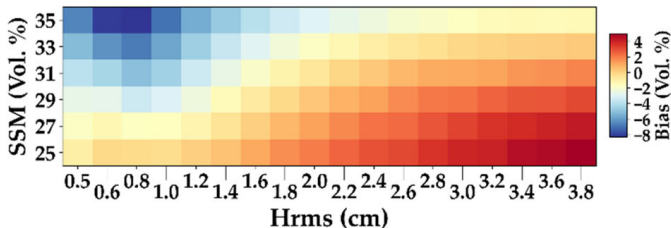

(a)

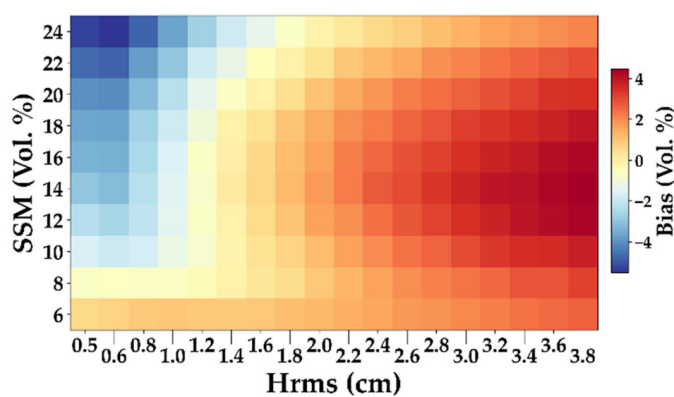

(c)

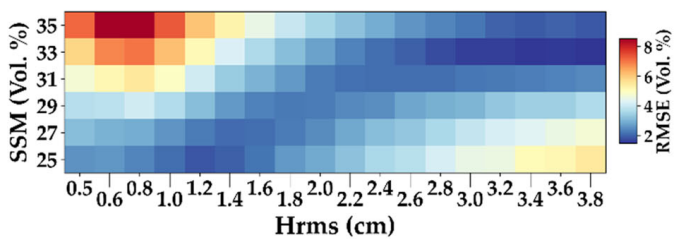

(e)

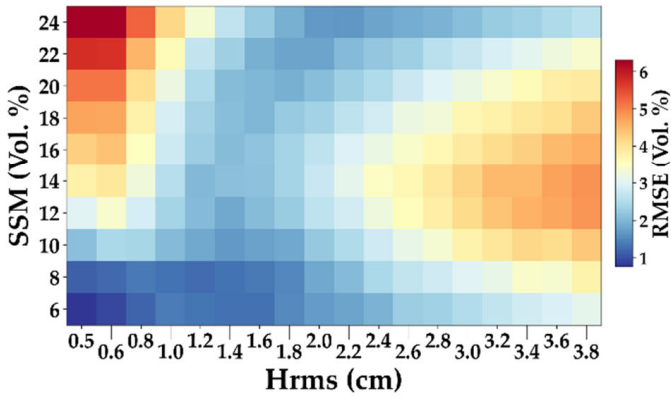

(g)

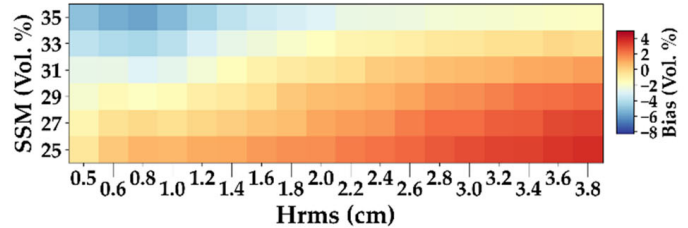

(b)

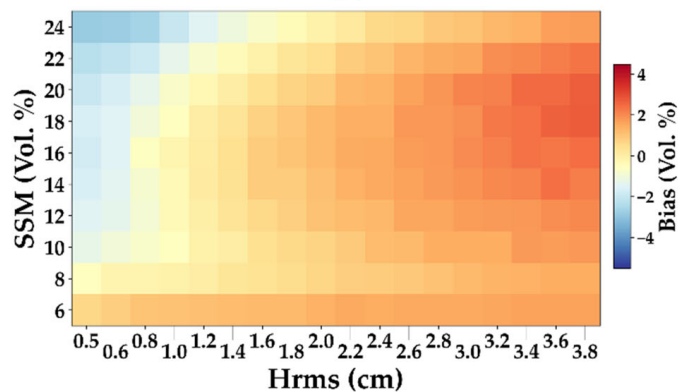

(d)

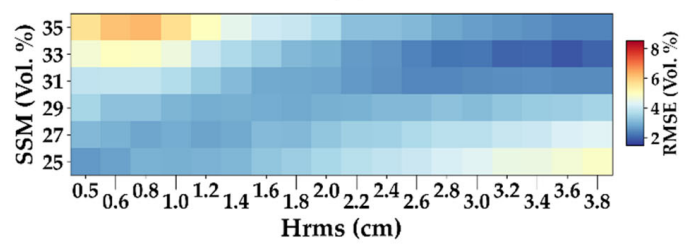

(f)

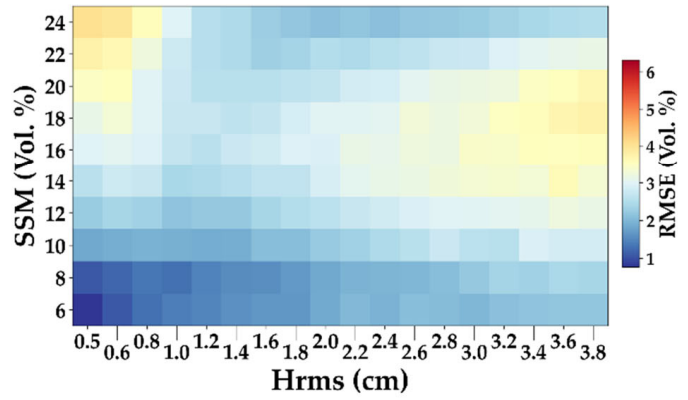

(h)

Figure 11. Bias (estimated SSM - reference SSM) and RMSE as a function of reference Hrms and SSM using simulated C-band data. (a,e) NN with a priori information on SSM for very wet soils without Hrms in input (NN11); (b,f) NN with a priori information on SSM for very wet soils with noisy Hrms in input (NN15); (c,g) NN with a priori information on SSM for dry to slightly wet soils without Hrms in input (NN6); (d,h) NN with a priori information on SSM for dry to slightly wet soils with noisy Hrms in input (NN10).

Moreover, the RMSE was analyzed according to SSM and Hrms (Figure 11e-h). For SSM values between 25 and 35 vol.\%, the RMSE is less than 4.0 vol.\% except for Hrms >1.6 $\mathrm{cm}$ and SSM values between 31 and 35 vol.\%. Higher RMSE values are observed when neglecting the Hrms effect (NN11) (Figure 11e) compared to the results obtained using NN15 (Figure 11f). In addition, at a Hrms $=0.8 \mathrm{~cm}$ and SSM $=35 \mathrm{vol} . \%$, the RMSE on the SSM estimations reached a maximum of 8.5 and 6.4 vol.\% when applying the NN11 and NN15, respectively.

For SSM values between 6 and 24 vol.\%, the developed NN10 with L-band-derived Hrms in input generates more accurate estimations compared to NN6, regardless of the SSM and Hrms values. Hence, a distinguishable improvement of the SSM estimation accuracy is mainly observed for low $\operatorname{Hrms}(<1.0 \mathrm{~cm})$ and SSM values greater than 14 vol.\%. 
In fact, the RMSE on NN6 estimations increased gradually with increasing SSM between 6 and 24 vol. $\%$ and Hrms lower than $1 \mathrm{~cm}$. The highest RMSE value is of 6.6 vol. $\%$ (Figure $11 \mathrm{~g}$ ), whereas in NN10 this value tends to decrease by 2 vol. $\%$ to reach $\approx 4.6$ vol.\% (Figure 11h). In addition, an enhancement (decrease in the RMSE) of the same magnitude was noticed when Hrms is greater than $2.4 \mathrm{~cm}$ and SSM ranges between 8 and 22 vol.\% (Figure 11g,h).

Furthermore, the NNs were evaluated using the real database. To examine more closely the improvement of the SSM estimations using real C-band data (Sentinel-1) and the estimated Hrms from the real L-band data (ALOS), the error on SSM (i.e., the bias and RMSE) was analyzed for different ranges of in situ Hrms and SSM using the NNs that neglect the Hrms effect (NN6 and NN11) as well as the NNs that use the estimated Hrms in the input vector (NN10 and NN15) (Figure 12). For the in situ SSM values lower than 15 vol. $\%$ and Hrms $\leq 1.5 \mathrm{~cm}, \mathrm{NN10}$ and NN15 provide a higher accuracy of SSM estimates compared to the results obtained using NN6 and NN11 (lower bias by 1.1 vol.\% and RMSE by 1.6 vol.\%). Similarly, when Hrms $>1.5 \mathrm{~cm}$ and SSM $<15$ vol. \%, the NNs neglecting Hrms (NN6 and NN11) overestimates the SSM by 7.5 vol.\% with an RMSE of 7.7 vol.\%, whereas the use of the estimated Hrms from the L-band (NN5 and NN10) yields a bias of 4.9 vol.\% with an RMSE of 5.5 vol.\%. Conversely, for in situ SSM higher than 15 vol.\%, no significant improvement was recorded on the SSM estimation using both approaches (neglecting or not the Hrms) for the different ranges of in situ Hrms (Figure 12a,b).

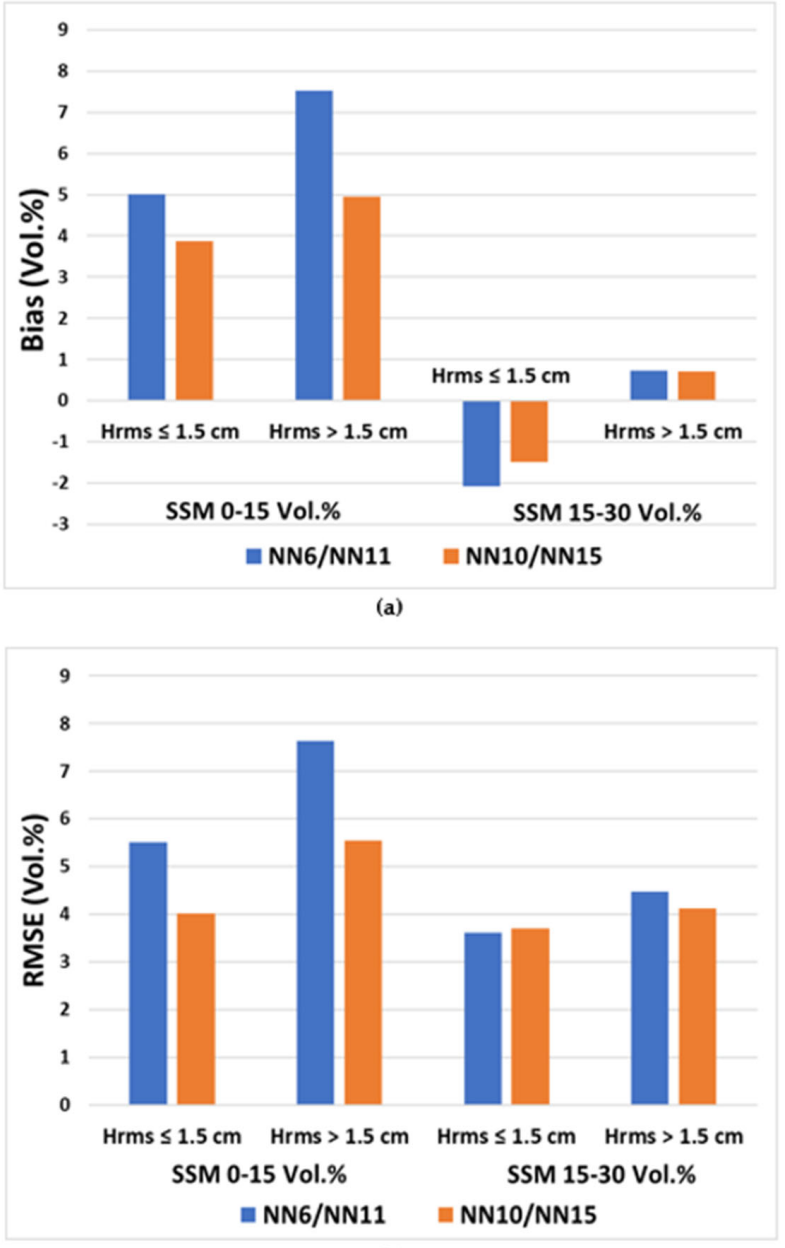

(b)

Figure 12. Calculated error on the retrieved SSM using C-band real SAR data versus in situ measurements. The inversion was performed using a priori information on SSM without using Hrms in the input vector (NN6/NN11) and with noisy Hrms in the input vector (NN9/NN14). (a) Bias (estimated SSM - in situ SSM); (b) RMSE. 
The arrival of the new SAR L-band sensors (some are planned to be launched in 2022) along with the continuous SAR Sentinel-1 data acquisition will allow an operational SSM mapping from the developed method (use the L-band-derived Hrms along with the C-band data). This will lead to a more accurate and improved SSM estimation in comparison to the use of C-band SAR data alone. Moreover, thanks to the higher penetration depth of the L-band SAR signal, the new L-band SAR data will permit a SSM estimation of soil under well-developed vegetation cover (NDVI > 0.7), which is not possible with the C-band data due to the SAR signal saturation [1]. Such SSM data availability and precision would make SSM estimation a convenient parameter to be used in many hydrological and agronomic applications. In particular, SAR-derived SSM could be used to calibrate crop models by data assimilation. A calibrated crop model is a reliable tool to improve yield through the optimization of agriculture practices such as, and not limited to, irrigation and fertilization.

\section{Conclusions}

This study aimed to investigate the interest of integrating L-band-derived Hrms to improve surface soil moisture (SSM) estimation from the C-band data over bare soils. The estimation approach uses the neural networks (NNs) trained on a synthetic database of SAR backscattering coefficients to invert the SAR signal and estimate soil parameters (SSM and Hrms). First the modified Integral Equation Model (IEM-B) was used to generate a synthetic database composed of backscattering coefficients (in the C-VV, C-VH and L-HH) with an incidence angle ranging from $20^{\circ}$ to $45^{\circ}$ over a wide range of SSM (between 6 and 36 vol. \%) and Hrms (between 0.5 and $3.8 \mathrm{~cm}$ ). Then, an absolute noise was added to the simulated backscattering coefficients to obtain a more realistic synthetic database. The developed NNs with C- and L-bands data were trained using the noisy synthetic database and validated using both synthetic and real databases to evaluate their performance for the estimation of SSM.

Thus, several NNs were built in order to assess the performance of the SSM estimation from the C-band (with and without Hrms in the input vector). In addition, a priori information on SSM was considered (dry to slightly wet SSM or very wet SSM). The results showed that the use of the non-noisy (reference) Hrms provide a better overall accuracy for the SSM estimates from C-band data compared to the case without the Hrms in the input vector of the NNs. In fact, an improvement of approximately 2.0 vol. $\%$ was observed on the RMSE (the RMSE was 4.33 vol.\% without using Hrms and 2.41 vol.\% when the nonnoisy Hrms is in the input vector). The results of the Hrms estimation using the synthetic database show that NNs built using the L-band data provide more accurate estimations of the Hrms compared to the NNs with the C-band. Indeed, the Hrms estimated from the L-band data showed an RMSE that ranged between 0.35 and $0.60 \mathrm{~cm}$ according to SSM and Hrms values, while the C-band results showed Hrms estimations with a lower accuracy and an RMSE ranging from 0.71 to $0.90 \mathrm{~cm}$. Thus, the estimation of the Hrms is more suitable using data in the L-band with a mean relative RMSE (RRMSE) of approximately $40 \%$ compared to $145 \%$ in the C-band.

Accordingly, a noisy Hrms of $40 \%$ along with C-band data were used to develop NNs for the estimation of SSM, in order to evaluate the potential of improving the SSM estimation compared to the NNs that neglect the Hrms in their inputs. In general, the results reported that consideration of a priori information improves the precision of the SSM estimates. The results showed that the error on the SSM estimation depends firmly on the SSM and Hrms. The NNs tend to underestimate and overestimate the SSM for Hrms values less and greater than $1.5 \mathrm{~cm}$, respectively, and the RMSE was the lowest (between 1.0 and 3.7 vol.\%) for intermediate Hrms values (Hrms between 1.5 and $2.0 \mathrm{~cm}$ ). Moreover, the developed NNs that consider the noisy Hrms in their input vector provided more accurate estimations of the SSM compared to those built neglecting the Hrms. In fact, for Hrms lower than $1.5 \mathrm{~cm}$ and SSM between 10 and 25 vol.\% as well as SSM ranging from 30 to 36 vol. $\%$, both the SSM underestimation (bias values up to -8.0 vol. $\%$ ) and the RMSE on SSM (reaching 8.5 vol.\%) decreased by 2.0 vol.\%, approximately, when the noisy Hrms is 
used in the NN input vector. Nonetheless, for Hrms between 1.5 and $2.0 \mathrm{~cm}$, no significant improvement was observed on the SSM estimation accuracy (RMSE around 2.5 vol.\%) and the overestimation decreased by less than 1.0 vol.\%. In addition, for Hrms values higher than $2.0 \mathrm{~cm}$ and SSM between 8 and 22 vol.\%, an improvement of the SSM estimation accuracy by about 2.0 vol. \% was observed and the SSM overestimation decreased from a maximum value of 4.5 to $2.3 \mathrm{vol} \%$ and the RMSE from 5.6 to $3.5 \mathrm{vol} . \%$.

The developed neural networks were applied on the real database. For the in situ SSM values lower than $15 \mathrm{vol} \%$, the results showed that the NNs with the Hrms estimated from ALOS/PALSAR as well as the Sentinel-1 signal in the input vector overestimate the SSM but provided more accurate SSM estimates than the NNs that do not consider the Hrms in their input vectors. More specifically, the overestimation decreases by 1.1 vol.\% for Hrms $<1.5 \mathrm{~cm}$ and by 2.6 vol. \% for Hrms $>1.5 \mathrm{~cm}$. However, for in situ SSM higher than 15 vol.\%, the L-band-derived Hrms did not show any significant improvement of the SSM estimation.

Author Contributions: Conceptualization, M.H. and N.B.; Data curation, M.H., M.M.E.H. and H.B.; Formal analysis, M.H. and N.B.; Methodology, M.H., N.B. and M.M.E.H.; Software, M.H. and M.M.E.H.; Supervision, N.B., B.C. and G.F.; Validation, M.H.; Writing-original draft, M.H.; Writing-review \& editing, N.B., M.M.E.H., M.Z., H.B., B.C. and G.F. All authors have read and agreed to the published version of the manuscript.

Funding: This research received funding from the French Space Study Center (CNES, TOSCA 2021 project), the National Research Institute for Agriculture, Food and the Environment (INRAE), the French Ministry of Foreign Affairs (French Embassy in Beirut) and the Lebanese National Council of Scientific Research.

Acknowledgments: The authors wish to thank the French Space Study Center (CNES, TOSCA 2021), the National Research Institute for Agriculture, Food and Environment (INRAE), Campus France and the Lebanese National Council of Scientific Research. The authors also wish to thank the European Space Agency (ESA) for the Sentinel-1 data. Moreover, the authors wish to thank the Japan Aerospace Exploration Agency (JAXA) for the distribution of PALSAR/ALOS images (ALOS PI 3023).

Conflicts of Interest: The authors declare no conflict of interest.

\section{References}

1. El Hajj, M.; Baghdadi, N.; Zribi, M. Comparative analysis of the accuracy of surface soil moisture estimation from the C- and L-bands. Int. J. Appl. Earth Obs. Geoinf. 2019, 82, 101888. [CrossRef]

2. François, C. The potential of directional radiometric temperatures for monitoring soil and leaf temperature and soil moisture status. Remote. Sens. Environ. 2002, 80, 122-133. [CrossRef]

3. Baghdadi, N.; Zribi, M. Microwave Remote Sensing of Land Surfaces. In Techniques and Methods; Elsevier: Amsterdam, The Netherlands, 2016.

4. Ulaby, F.T.; Moore, R.K.; Fung, A.K. Microwave Remote Sensing: Active and Passive. Volume I: Microwave Remote Sensing Fundamentals and Radiometry. In Microwave Remote Sensing Fundamentals and Radiometry; Artech House: Norwood, MA, USA, 1981.

5. El Hajj, M.; Baghdadi, N.; Zribi, M.; Bazzi, H. Synergic Use of Sentinel-1 and Sentinel-2 Images for Operational Soil Moisture Mapping at High Spatial Resolution over Agricultural Areas. Remote. Sens. 2017, 9, 1292. [CrossRef]

6. Piles, M.; Sanchez, N.; Vall-Llossera, M.; Camps, A.; Martinez-Fernandez, J.; Martinez, J.; Gonzalez-Gambau, V. A Downscaling Approach for SMOS Land Observations: Evaluation of High-Resolution Soil Moisture Maps Over the Iberian Peninsula. IEEE J. Sel. Top. Appl. Earth Obs. Remote. Sens. 2014, 7, 3845-3857. [CrossRef]

7. Knipper, K.R.; Hogue, T.S.; Franz, K.J.; Scott, R.L. Downscaling SMAP and SMOS soil moisture with moderate-resolution imaging spectroradiometer visible and infrared products over southern Arizona. J. Appl. Remote. Sens. 2017, 11, 026021. [CrossRef]

8. Wagner, W.; Pathe, C.; Doubkova, M.; Sabel, D.; Bartsch, A.; Hasenauer, S.; Blöschl, G.; Scipal, K.; Martínez-Fernández, J.; Löw, A. Temporal Stability of Soil Moisture and Radar Backscatter Observed by the Advanced Synthetic Aperture Radar (ASAR). Sensors 2008, 8, 1174-1197. [CrossRef]

9. Balenzano, A.; Mattia, F.; Satalino, G.; Davidson, M.W.J. Dense Temporal Series of C- and L-band SAR Data for Soil Moisture Retrieval Over Agricultural Crops. IEEE J. Sel. Top. Appl. Earth Obs. Remote. Sens. 2011, 4, 439-450. [CrossRef]

10. Anguela, T.P.; Zribi, M.; Hasenauer, S.; Habets, F.; Loumagne, C. Analysis of surface and root-zone soil moisture dynamics with ERS scatterometer and the hydrometeorological model SAFRAN-ISBA-MODCOU at Grand Morin watershed (France). Hydrol. Earth Syst. Sci. 2008, 12, 1415-1424. [CrossRef] 
11. Alvarez-Mozos, J.; Casali, J.; Gonzalez-Audicana, M.; Verhoest, N. Assessment of the operational applicability of RADARSAT-1 data for surface soil moisture estimation. IEEE Trans. Geosci. Remote Sens. 2006, 44, 913-924. [CrossRef]

12. Şekertekin, A.; Marangoz, A.M.; Abdikan, S. Soil Moisture Mapping Using Sentinel-1A Synthetic Aperture Radar Data. Int. J. Env. Geoinform. 2018, 5, 178-188. [CrossRef]

13. Gao, Q.; Zribi, M.; Escorihuela, M.J.; Baghdadi, N. Synergetic Use of Sentinel-1 and Sentinel-2 Data for Soil Moisture Mapping at $100 \mathrm{~m}$ Resolution. Sensors 2017, 17, 1966. [CrossRef] [PubMed]

14. Aubert, M.; Baghdadi, N.N.; Zribi, M.; Ose, K.; El Hajj, M.; Vaudour, E.; Gonzalez-Sosa, E. Toward an Operational Bare Soil Moisture Mapping Using TerraSAR-X Data Acquired Over Agricultural Areas. IEEE J. Sel. Top. Appl. Earth Obs. Remote. Sens. 2012, 6, 900-916. [CrossRef]

15. El Hajj, M.; Baghdadi, N.; Belaud, G.; Zribi, M.; Cheviron, B.; Courault, D.; Hagolle, O.; Charron, F. Irrigated Grassland Monitoring Using a Time Series of TerraSAR-X and COSMO-SkyMed X-Band SAR Data. Remote. Sens. 2014, 6, 10002-10032. [CrossRef]

16. Baghdadi, N.; Cerdan, O.; Zribi, M.; Auzet, V.; Darboux, F.; El Hajj, M.; Kheir, R.B. Operational performance of current synthetic aperture radar sensors in mapping soil surface characteristics in agricultural environments: Application to hydrological and erosion modelling. Hydrol. Process. 2007, 22, 9-20. [CrossRef]

17. Baghdadi, N.; Cresson, R.; El Hajj, M.; Ludwig, R.; La Jeunesse, I. Estimation of soil parameters over bare agriculture areas from C-band polarimetric SAR data using neural networks. Hydrol. Earth Syst. Sci. 2012, 16, 1607-1621. [CrossRef]

18. Mirsoleimani, H.R.; Sahebi, M.R.; Baghdadi, N.; El Hajj, M. Bare Soil Surface Moisture Retrieval from Sentinel-1 SAR Data Based on the Calibrated IEM and Dubois Models Using Neural Networks. Sensors 2019, 19, 3209. [CrossRef] [PubMed]

19. Baghdadi, N.; King, C.; Bourguignon, A.; Remond, A. Potential of ERS and Radarsat data for surface roughness monitoring over bare agricultural fields: Application to catchments in Northern France. Int. J. Remote. Sens. 2002, 23, 3427-3442. [CrossRef]

20. Ulaby, F.T.; Batlivala, P.P.; Dobson, M.C. Microwave Backscatter Dependence on Surface Roughness, Soil Moisture, and Soil Texture: Part I-Bare Soil. IEEE Trans. Geosci. Electron. 1978, 16, 286-295. [CrossRef]

21. le Toan, T. Active microwave signatures of soil and crops. significant results of three years of experiments. In Proceedings of the Digest-International Geoscience and Remote Sensing Symposium (IGARSS), Munich, Germany, 1-4 June 1982.

22. Zribi, M.; Gorrab, A.; Baghdadi, N.; Lili-Chabaane, Z.; Mougenot, B. Influence of Radar Frequency on the Relationship Between Bare Surface Soil Moisture Vertical Profile and Radar Backscatter. IEEE Geosci. Remote. Sens. Lett. 2014, 11, 848-852. [CrossRef]

23. Beaudoin, A.; Le Toan, T.; Gwyn, Q. SAR observations and modeling of the C-band backscatter variability due to multiscale geometry and soil moisture. IEEE Trans. Geosci. Remote. Sens. 1990, 28, 886-895. [CrossRef]

24. Baghdadi, N.; Saba, E.; Aubert, M.; Zribi, M.; Baup, F. Comparison between Backscattered TerraSAR Signals and Simulations from the Radar Backscattering Models IEM, Oh, and Dubois. IEEE Geosci. Remote Sens. Lett. 2011, 6, 1160-1164. [CrossRef]

25. Aubert, M.; Baghdadi, N.; Zribi, M.; Douaoui, A.; Loumagne, C.; Baup, F.; El Hajj, M.; Garrigues, S. Analysis of TerraSAR-X data sensitivity to bare soil moisture, roughness, composition and soil crust. Remote. Sens. Env. 2011, 115, 1801-1810. [CrossRef]

26. Narvekar, P.S.; Entekhabi, D.; Kim, S.-B.; Njoku, E.G. Soil Moisture Retrieval Using L-Band Radar Observations. IEEE Trans. Geosci. Remote. Sens. 2015, 53, 3492-3506. [CrossRef]

27. Fung, A.K. Microwave Scattering and Emission Models and Their Applications; Artech House Publishers: Norwood, MA, USA, 1994.

28. Chen, K.; Wu, T.-D.; Tsang, L.; Li, Q.; Shi, J.; Fung, A. Emission of rough surfaces calculated by the integral equation method with comparison to three-dimensional moment method simulations. IEEE Trans. Geosci. Remote. Sens. 2003, 41, 90-101. [CrossRef]

29. Baghdadi, N.; Choker, M.; Zribi, M.; El Hajj, M.; Paloscia, S.; Verhoest, N.E.C.; Lievens, H.; Baup, F.; Mattia, F. A New Empirical Model for Radar Scattering from Bare Soil Surfaces. Remote. Sens. 2016, 8, 920. [CrossRef]

30. Dubois, P.; Van Zyl, J.; Engman, T. Measuring soil moisture with imaging radars. IEEE Trans. Geosci. Remote. Sens. 1995, 33, 915-926. [CrossRef]

31. Oh, Y. Quantitative Retrieval of Soil Moisture Content and Surface Roughness from Multipolarized Radar Observations of Bare Soil Surfaces. IEEE Trans. Geosci. Remote. Sens. 2004, 42, 596-601. [CrossRef]

32. Gorrab, A.; Zribi, M.; Baghdadi, N.; Mougenot, B.; Fanise, P.; Chabaane, Z.L. Retrieval of Both Soil Moisture and Texture Using TerraSAR-X Images. Remote. Sens. 2015, 7, 10098-10116. [CrossRef]

33. Panciera, R.; Tanase, M.A.; Lowell, K.; Walker, J.P. Evaluation of IEM, Dubois, and Oh Radar Backscatter Models Using Airborne L-Band SAR. IEEE Trans. Geosci. Remote. Sens. 2014, 52, 4966-4979. [CrossRef]

34. Baghdadi, N.; Gaultier, S.; King, C. Retrieving surface roughness and soil moisture from synthetic aperture radar (SAR) data using neural networks. Can. J. Remote. Sens. 2002, 28, 701-711. [CrossRef]

35. Zribi, M.; Taconet, O.; Le Hégarat-Mascle, S.; Vidal-Madjar, D.; Emblanch, C.; Loumagne, C.; Normand, M. Backscattering behavior and simulation comparison over bare soils using SIR-C/X-SAR and ERASME 1994 data over Orgeval. Remote. Sens. Environ. 1997, 59, 256-266. [CrossRef]

36. Baghdadi, N.; Chaaya, J.A.; Zribi, M. Semiempirical Calibration of the Integral Equation Model for SAR Data in C-Band and Cross Polarization Using Radar Images and Field Measurements. IEEE Geosci. Remote. Sens. Lett. 2010, 8, 14-18. [CrossRef]

37. Baghdadi, N.; Holah, N.; Zribi, M. Calibration of the Integral Equation Model for SAR data in C-band and HH and VV polarizations. Int. J. Remote. Sens. 2006, 27, 805-816. [CrossRef]

38. Baghdadi, N.; Gherboudj, I.; Zribi, M.; Sahebi, M.; King, C.; Bonn, F. Semi-empirical calibration of the IEM backscattering model using radar images and moisture and roughness field measurements. Int. J. Remote. Sens. 2004, 25, 3593-3623. [CrossRef] 
39. Baghdadi, N.; Zribi, M.; Paloscia, S.; Verhoest, N.E.C.; Lievens, H.; Baup, F.; Mattia, F. Semi-Empirical Calibration of the Integral Equation Model for Co-Polarized L-Band Backscattering. Remote. Sens. 2015, 7, 13626-13640. [CrossRef]

40. Paloscia, S.; Pettinato, S.; Santi, E.; Notarnicola, C.; Pasolli, L.; Reppucci, A. Soil moisture mapping using Sentinel-1 images: Algorithm and preliminary validation. Remote. Sens. Environ. 2013, 134, 234-248. [CrossRef]

41. Srivastava, H.S.; Patel, P.; Sharma, Y.; Navalgund, R.R. Large-Area Soil Moisture Estimation Using Multi-Incidence-Angle RADARSAT-1 SAR Data. IEEE Trans. Geosci. Remote. Sens. 2009, 47, 2528-2535. [CrossRef]

42. Baghdadi, N.; Cresson, R.; Pottier, E.; Aubert, M.; Mehrez, M.; Jacome, A.; Benabdallah, S. A Potential Use for the C-Band Polarimetric SAR Parameters to Characterize the Soil Surface Over Bare Agriculture Fields. IEEE Trans. Geosci. Remote. Sens. 2012, 50, 3844-3858. [CrossRef]

43. Zribi, M.; Baghdadi, N.; Holah, N.; Fafin, O. New methodology for soil surface moisture estimation and its application to ENVISAT-ASAR multi-incidence data inversion. Remote. Sens. Environ. 2005, 96, 485-496. [CrossRef]

44. Altese, E.; Bolognani, O.; Troch, P.A.; Mancini, M. Retrieving Soil Moisture Over Bare Soil from ERS 1 Synthetic Aperture Radar Data: Sensitivity Analysis Based on a Theoretical Surface Scattering Model and Field Data. Water Resour. Res. 1996, 32, 653-661. [CrossRef]

45. Mattia, F.; Davidson, M.W.J.; le Toan, T.; D’Haese, C.M.F.; Verhoest, N.E.C.; Gatti, A.M.; Borgeaud, M. A Comparison between Soil Roughness Statistics Used in Surface Scattering Models Derived from Mechanical and Laser Profilers. IEEE Trans. Geosci. Remote. Sens. 2003, 41, 1659-1671. [CrossRef]

46. Davidson, M.; Mattia, F.; Satalino, G.; Verhoest, N.; Le Toan, T.; Borgeaud, M.; Louis, J.; Attema, E. Joint statistical properties of rms height and correlation length derived from multisite 1-m roughness measurements. IEEE Trans. Geosci. Remote. Sens. 2003, 41, 1651-1658. [CrossRef]

47. Remond, A.; Beaudoin, A.; King, C. SAR imagery to estimate roughness parameters when modelling runoff risk. Int. J. Remote. Sens. 1999, 20, 2613-2625. [CrossRef]

48. Michelson, D.B. ERS-I SAR backscattering coefficients from bare fields with different tillage row directions. Int. J. Remote. Sens. 1994, 15, 2679-2685. [CrossRef]

49. Oh, Y.; Sarabandi, K.; Ulaby, F.T. An empirical model and an inversion technique for radar scattering from bare soil surfaces. IEEE Trans. Geosci. Remote Sens. 1992, 30, 370-381. [CrossRef]

50. Dobson, M.C.; Ulaby, F.T. Active Microwave Soil Moisture Research. IEEE Trans. Geosci. Remote. Sens. 1986, GE-24, 23-26. [CrossRef]

51. Ulaby, F.T.; Bare, J.E. Look Direction Modulation Function of the Radar Backscattering Coefficient of Agricultural Fields. Photogrammetric Engineering and Remote Sensing. 1979. Available online: https://www.asprs.org/wp-content/uploads/pers/ 1979journal/nov/1979_nov_1495-1506.pdf (accessed on 6 April 2021).

52. Mattia, F.; Le Toan, T. Backscattering Properties of Multi-Scale Rough Surfaces. J. Electromagn. Waves Appl. 1999, $13,493-527$. [CrossRef]

53. Davidson, M.; Le Toan, T.; Mattia, F.; Satalino, G.; Manninen, T.; Borgeaud, M. On the characterization of agricultural soil roughness for radar remote sensing studies. IEEE Trans. Geosci. Remote. Sens. 2000, 38, 630-640. [CrossRef]

54. Wagner, W.; Bloschl, G.; Pampaloni, P.; Calvet, J.-C.; Bizzarri, B.; Wigneron, J.-P.; Kerr, Y. Operational readiness of microwave remote sensing of soil moisture for hydrologic applications. Hydrol. Res. 2007, 38, 1-20. [CrossRef]

55. Shi, J.; Wang, J.; Hsu, A.; O'Neill, P.; Engman, E. Estimation of bare surface soil moisture and surface roughness parameter using L-band SAR image data. IEEE Trans. Geosci. Remote. Sens. 1997, 35, 1254-1266. [CrossRef]

56. Shi, J.; Wang, J.; Hsu, A.; O'Neili, P.; Engman, E. Estimation of soil moisture and surface roughness parameters using L-band SAR measurements. IEEE Trans. Geosci. Remote. Sens. 2002, 1, 507-509.

57. Tomer, S.K.; Al Bitar, A.; Sekhar, M.; Zribi, M.; Bandyopadhyay, S.; Sreelash, K.; Sharma, A.; Corgne, S.; Kerr, Y. Retrieval and Multi-scale Validation of Soil Moisture from Multi-temporal SAR Data in a Semi-Arid Tropical Region. Remote. Sens. 2015, 7, 8128-8153. [CrossRef]

58. Van Doninck, J.; Peters, J.; Lievens, H.; De Baets, B.; Verhoest, N.E.C. Accounting for seasonality in a soil moisture change detection algorithm for ASAR Wide Swath time series. Hydrol. Earth Syst. Sci. 2012, 16, 773-786. [CrossRef]

59. Baghdadi, N.N.; El Hajj, M.; Zribi, M.; Fayad, I. Coupling SAR C-Band and Optical Data for Soil Moisture and Leaf Area Index Retrieval Over Irrigated Grasslands. IEEE J. Sel. Top. Appl. Earth Obs. Remote. Sens. 2015, 9, 1229-1243. [CrossRef]

60. Mattia, F.; Le Toan, T.; Souyris, J.-C.; De Carolis, C.; Floury, N.; Posa, F.; Pasquariello, N. The effect of surface roughness on multifrequency polarimetric SAR data. IEEE Trans. Geosci. Remote. Sens. 1997, 35, 954-966. [CrossRef]

61. Antoni, V.; Arrouays, D.; Bispo, A.; Brossard, M.; le Bas, C.; Stengel, P.; Villanneau, E.; Baize, D.; Barriuso, E.; Blanca, Y.; et al. Synthèse Sur l'état Des Sols de France. 2011. Available online: https:/ / www.inrae.fr/sites/default/files/synthese_etat_sol_0.pdf (accessed on 6 April 2021).

62. Chai, S.-S.; Walker, J.P.; Makarynskyy, O.; Kuhn, M.; Veenendaal, B.; West, G. Use of Soil Moisture Variability in Artificial Neural Network Retrieval of Soil Moisture. Remote. Sens. 2009, 2, 166-190. [CrossRef]

63. Schwerdt, M.; Schmidt, K.; Ramon, N.T.; Klenk, P.; Yague-Martinez, N.; Prats-Iraola, P.; Zink, M.; Geudtner, D. Independent System Calibration of Sentinel-1B. Remote. Sens. 2017, 9, 511. [CrossRef] 
64. Motohka, T.; Isoguchi, O.; Sakashita, M.; Shimada, M. Results of ALOS-2 PALSAR-2 Calibration and Validation After 3 Years of Operation. In Proceedings of the IGARSS 2018-2018 IEEE International Geoscience and Remote Sensing Symposium, Valencia, Spain, 22-27 July 2018; pp. 4169-4170.

65. Marquardt, D.W. An Algorithm for Least-Squares Estimation of Nonlinear Parameters. J. Soc. Ind. Appl. Math. 1963, 11, 431-441. [CrossRef]

66. Satalino, G.; Mattia, F.; Davidson, M.; Le Toan, T.; Pasquariello, G.; Borgeaud, M. On current limits of soil moisture retrieval from ERS-SAR data. IEEE Trans. Geosci. Remote. Sens. 2002, 40, 2438-2447. [CrossRef]

67. Boisvert, J.B.; Gwyn, Q.H.J.; Chanzy, A.; Major, D.J.; Brisco, B.; Brown, R.J. Effect of surface soil moisture gradients on modelling radar backscattering from bare fields. Int. J. Remote. Sens. 1997, 18, 153-170. [CrossRef]

68. Bindlish, R. Multifrequency Soil Moisture Inversion from SAR Measurements with the Use of IEM. Remote. Sens. Env. 2000, 71, 67-88. [CrossRef]

69. Rakotoarivony, L.; Taconet, O.; Vidal-Madjar, D.; Bellemain, P.; Benallegue, M. Radar backscattering over agricultural bare soils. J. Electromagn. Waves Appl. 1996, 10, 187-209. [CrossRef]

70. Leconte, R.; Brissette, F.; Galarneau, M.; Rousselle, J. Mapping near-surface soil moisture with RADARSAT-1 synthetic aperture radar data. Water Resour. Res. 2004, 40, 40. [CrossRef]

71. Baghdadi, N.; King, C.; Chanzy, A.; Wigneron, J.P. An empirical calibration of the integral equation model based on SAR data, soil moisture and surface roughness measurement over bare soils. Int. J. Remote. Sens. 2002, 23, 4325-4340. [CrossRef]

72. Ulaby, F.T.; Dubois, P.C.; van Zyl, J. Radar mapping of surface soil moisture. J. Hydrol. 1996, 184, 57-84. [CrossRef] 